\title{
Reggie-1/Flotillin-2 regulates integrin trafficking and focal adhesion turnover via Rab11a
}

\author{
Nikola Hülsbusch ${ }^{\mathrm{a}, *}$, Gonzalo P. Solis ${ }^{\mathrm{b}}$, Vladimir L. Katanaev ${ }^{\mathrm{b}}$, Claudia A.O. Stuermer ${ }^{\mathrm{a}, *}$ \\ a Department of Biology, University of Konstanz, 78467 Konstanz, Germany \\ ${ }^{\mathrm{b}}$ Department of Pharmacology and Toxicology, University of Lausanne, CH-1005 Lausanne, Switzerland
}

\section{A R T I C L E I N F O}

Keywords:

Reggie/flotillin

Focal adhesion

Integrin

Rab11

Cargo trafficking

Targeted delivery

\begin{abstract}
A B S T R A C T
Reggies/flotillins are implicated in trafficking of membrane proteins to their target sites and in the regulation of the Rab11a-dependent targeted recycling of E-cadherin to adherens junctions (AJs). Here we demonstrate a function of reggies in focal adhesion (FA) formation and $\alpha 5$ - and $\beta 1$-integrin recycling to FAs. Downregulation of reggie-1 in HeLa and A431 cells by siRNA and shRNA increased the number of FAs, impaired their distribution and modified FA turnover. This was coupled to enhanced focal adhesion kinase (FAK) and Rac1 signaling and gain in plasma membrane motility. Wild type and constitutively-active (CA) Rab11a rescued the phenotype (normal number of FAs) whereas dominant-negative (DN) Rab11a mimicked the loss-of-reggie phenotype in control cells. That reggie-1 affects integrin trafficking emerged from the faster loss of internalized antibody-labeled $\beta 1$-integrin in reggie-deficient cells. Moreover, live imaging using TIRF microscopy revealed vesicles containing reggie- 1 and $\alpha 5$ - or $\beta 1$-integrin, trafficking close to the substrate-near membrane and making kiss-and-run contacts with FAs. Thus, reggie- 1 in interaction with Rab11a controls Rac1 and FAK activation and coordinates the targeted recycling of $\alpha 5$ and $\beta 1$-integrins to FAs to regulate FA formation and membrane dynamics.
\end{abstract}

\section{Introduction}

Integrins are heterodimeric receptors, composed of $\alpha$ - and $\beta$ subunits which are involved in the formation of FAs. Integrin $\alpha-$ and $\beta$-subunits assemble in a cell-type specific manner and serve as receptors for distinct extracellular matrix proteins, soluble ligands and RGD-containing proteins (Margadant et al., 2011).

During cell migration, integrins and FAs undergo rapid turnover (Margadant et al., 2011), a process that includes recycling and the targeted re-delivery of integrins and integrin-interacting components to newly forming focal contacts and nascent FAs (Caswell et al., 2009). Integrin recycling requires EHD1- (epsin homology domain containing protein 1 ) positive cargo vesicle trafficking controlled by Rab and Rho-GTPases and the cytoskeleton (Caswell et al., 2009; Grant and Donaldson, 2009; Jovic et al., 2007). Rab11, a key player in cargo recycling, is therefore indispensable for FA

Abbreviations: AJ, adherens junction; Ab, antibody; CA, constitutively active; DN, dominant negative; FA, focal adhesion; FAK, focal adhesion kinase; FN, fibronectin; PLL, poly-L-lysine; wt, wildtype.

* Corresponding authors. Tel.: +49 7531882236.

E-mail addresses: Nikola.Huelsbusch@uni-Konstanz.de (N. Hülsbusch), Claudia.Stuermer@uni-Konstanz.de (C.A.O. Stuermer). formation and cell migration (Arjonen et al., 2012; Bridgewater et al., 2012; Eva et al., 2010). Integrin and E-cadherin trafficking are also influenced by Src and FAK (Canel et al., 2013). These kinases seem to regulate whether cells increase their migratory activity by integrin activation or their engagement in cell-cell adhesion by Ecadherin activation (Canel et al., 2013). How integrins are targeted to the plasma membrane and FAs is still incompletely understood.

The streak-like FAs resemble to some extent adherens junctions (AJs) which are adhesive structures that are dependent on Ecadherin, the homophilic cell adhesion protein involved in cell-cell interaction. Cell adhesion between epithelial cells depends on the dynamic turnover of E-cadherin and AJs which involves Rab11 and the balanced activation of Rho GTPases (Grant and Donaldson, 2009; Ivanov and Naydenov, 2013). We and others have recently recognized that the reggie/flotillin proteins participate in cell adhesion (Guillaume et al., 2013; Kurrle et al., 2013; Solis et al., 2012). Our work has shown that reggies regulate $\mathrm{AJ}$ formation and the Rab11a-dependent turnover of E-cadherin in A431 cells (Solis et al., 2012, 2013) and N-cadherin deployment in axonal growth cones of hippocampal neurons (Bodrikov et al., 2011). Reggies/flotillins form oligomeric clusters in lipid rafts at the cytoplasmic face of the plasma membrane and at specific trafficking vesicles (Solis et al., 2007, 2013). We identified reggies as associates of the Rab11a-positive tubulo-vesicular recycling compartment where 
they co-cluster with membrane deforming BAR proteins, SNX4 and EHD1 and directly interact with Rab11a and SNX4 (Solis et al., 2013). Reggie-deficient cells presented abnormal AJs and migrated faster in a wound-closure assay (Solis et al., 2012). This correlated with abnormal E-cadherin trafficking and changes in the activation state of Rho and Rab family GTPases after reggie- 1 knockdown (Solis et al., 2012, 2013).

The accelerated cell migration after reggie downregulation and the interaction with CAP (c-cbl-associated protein), a component of FAs, which is known to bind reggie-2 (Kimura et al., 2001; Kioka et al., 2002; Langhorst et al., 2008a), suggested that reggies might also play a role in FA formation (Schmidt and Dikic, 2005). Indeed, a proteomic analysis previously recognized that reggie1 and reggie-2 are part of the FA complex (Kuo et al., 2011). In addition, the downregulation of reggie and overexpression of a dominant negative (DN) reggie-1 construct disturbed the localization of overexpressed prion protein in structures resembling FAs (Schrock et al., 2009), affected Src and FAK and impaired axon growth (Langhorst et al., 2008a; Munderloh et al., 2009). As reggies were, furthermore, implicated in the delivery of the $\mathrm{T}$ cell receptor to the T cell cap (Stuermer et al., 2004) and in Rab11a-dependent E-cadherin recycling (Solis et al., 2013), we concluded that reggies might regulate as well integrin recycling and FA dynamics through Rab11a (Stuermer, 2010).

Here, we investigated whether reggie- 1 is involved in the regulation of integrin dependent FAs in analogy to its role in AJ formation, and whether integrin trafficking depends on the interaction of reggie with Rab11a. Indeed, downregulation of reggie- 1 by siRNA and shRNA affected FA number, distribution and turnover in HeLa and A431 cells and increased membrane motility on fibronectin (FN) in correlation with a rise in Rac1 and FAK activity. We show (by Colibri and TIRF microscopy in live HeLa cells) that reggie- 1 traffics together with $\alpha 5$ - and $\beta 1$-integrin. The reggie-dependent increase in FA number was rescued by a Rab11a wildtype (wt) and a Rab11a constitutively active (CA) mutant construct, and was mimicked by Rab11 DN.

Thus, we show that the influence of reggie on the Rab11adependent recycling process has extensive effects on FA number and distribution, integrin trafficking, membrane motility and the regulation of cell-matrix adhesion.

\section{Materials and methods}

\section{Reagents and antibodies}

All cell culture reagents were purchased from Gibco BRL. Monoclonal antibodies (mAbs) against Paxillin, FAK, $\beta 1$-integrin, Rac1, reggie-2 (flotillin-1) and reggie-1 (ESA) were from BD Biosciences, $\mathrm{mAb}$ against $\beta 1$-integrin (12G10) from Biorad, mAb against GFP from Roche, polyclonal antibody (pAb) against R1 (clone 1680) from Sigma, pAb against $\alpha 5$-integrin from Santa Cruz Biotechnology, pAbs against $\alpha$-tubulin and GAPDH from Abcam, pAb against Rab11FIP1 (RCP) was a kind gift from Rytis Prekeris (University of Colorado, Denver), anti phospho-pAbs against pFAK (Y576/577), Pyk2 and pPaxillin were purchased from Cell Signaling. The PAK-1 PBD agarose conjugated Rac1-GTP assay reagent was purchased from Upstate and all secondary Abs for Western blots and immunostaining from Jackson ImmunoResearch.

\section{Plasmids}

The R1-mRFP and R1-EGFP-rescue vectors have been previously described (Langhorst et al., 2007; Solis et al., 2007, 2012). The mCherry-Rab11a construct and the $\alpha 5$-integrin-EGFP vector were kindly provided by Richard Eva (University of Cambridge,
UK) and Donna Web (University of Virginia, Charlottesville, USA). The $\beta 1$-integrin-GFP was a kind gift from Sue Craig (University of Manchester, UK). EGFP-Rab11a Q70L and S25N mutants were kindly provided by Stephen Ferguson (University of Western Ontario, Canada) and the mRFP-Rab11a mutants were created by replacing the EGFP-ORF by mRFP from the pmRFP-C1 vector (Solis et al., 2012). The GFP-Paxillin construct was a gift from Kenneth Yamada (Bethesda, Maryland, USA). The EGFP-Rab4a wt was obtained from Marci Scidmore (Cornell University, NY, USA), the ECFP-Rab4a DN was a kind gift from Ralf Jacob (University of Marburg, Germany) and mRFP-Rab8a wt from Johan Peränen (University of Helsinki, Finland).

\section{Cell culture}

HeLa and A431 cells were cultured in MEM and DMEM, respectively and supplemented with $10 \%$ FCS, penicillin/streptomycin and L-glutamine. Vector transfection was performed with Lipofectamine (Life Technologies) for $48 \mathrm{~h}$ and siRNA transfection was carried out with the Nanofectine siRNA transfection reagent (PAA) for $72 \mathrm{~h}$, all according to the manufacturer's instructions. Labeled (AlexaFluor546) siRNA duplexes against R1 (R1.0) or luciferase from firefly (GL2) were purchased from Quiagen according to target sequences described previously (Solis et al., 2007).

\section{Stable transfected cell lines}

HeLa and A431 cells with stable knockdown were obtained by using shRNA plasmids (Solis et al., 2012). Cells were selected in normal growth medium supplemented with $10 \mu \mathrm{g} / \mathrm{ml}$ puromycin. Stably transfected HeLa and A431 cells (shLuc and shR1.0) were described previously (Solis et al., 2012, 2013). A second HeLa cell line for the downregulation of reggie-1 (shR1.1) was obtained using the primers $5^{\prime}$ sense strand, 5' -gatccccGTTCATGGCAGACACCAAGttcaagagaCTTGGTGTCTGCCATGAACttttta-3', and 3' antisense strand, 5'-agcttaaaaaGTTCATGGCAGACACCAAGtctcttgaaCTTGGTGTCTGCCATGAACggg- $3^{\prime}$. Annealed primers were cloned using the BamHI and HindIII sites of the pRetroSuper vector. Cells were selected and further cultured in $10 \mu \mathrm{g} / \mathrm{ml}$ puromycin.

\section{Immunofluorescence and microscopy}

HeLa and A431 cells were fixed with PFA, washed with PBS and permeabilized with PBS containing $0.01 \%$ Triton-X-100. After additional washing steps, cells were blocked with $1 \%$ bovine serum albumin (BSA) in PBS. Immunostaining was performed overnight with the corresponding Abs. After three washes with PBS, cells were incubated with the secondary Abs for $1.5 \mathrm{~h}$, followed by washing steps with PBS and MilliQ water. The coverslips were mounted with Mowiol (Sigma-Aldrich) and dried at $4{ }^{\circ} \mathrm{C}$. Microscopy was performed by a Plan-Apochromat $63 \times / 1.4$ oil objective or an Apochromat $40 \times / 1.2 \mathrm{~W}$ objective at a confocal microscope (LSM700, Zeiss, Jena). For the live staining, cells were washed with cold PBS, incubated with the $\mathrm{Ab}$, diluted in cold medium, at $4{ }^{\circ} \mathrm{C}$ for $1 \mathrm{~h}$, fixed and immunostained without permeabilization as described above.

\section{Spreading assay}

HeLa shLuc and shR1 cells were trypsinized (0.05\% TrypsinEDTA, Gibco) for $3 \mathrm{~min}$, centrifuged, resuspended in normal growth medium and plated onto FN-coated coverslips.

After $2 \mathrm{~h}$ of spreading, cells were fixed with PFA, permeabilized and immunostained with paxillin and phalloidin as described above. The size of more than 340 shLuc and shR1 cells, respectively, 
was measured in three independent experiments with Axiovision Rel. 4.8. Statistical analysis was performed using the paired $t$-test.

\section{Live imaging of overexpressed proteins}

Cells were seeded onto $\mu$-dishes with glass-bottom (ibidi) coated with FN and transfected as described above. After $48 \mathrm{~h}$ cells were recorded with a Colibri Cell Observer SD system, a widefield fluorescence microscope equipped with LED as light source $(470 \mathrm{~nm}$ and $555 \mathrm{~nm}$ at $100 \%$ power) with an $\alpha$-Plan Fluar $100 \times / 1.45$ objective at $37^{\circ} \mathrm{C}$ and $5 \% \mathrm{CO}_{2}$ every second for $5 \mathrm{~min}$ to monitor co-trafficking of two different proteins or every $30 \mathrm{sec}$ for $1 \mathrm{~h}$ to record the movement of FAs with a AxioCamHRm (all from Zeiss). Data were analyzed in Axiovision 4.8 (Zeiss) or Image (National Institutes of Health, Bethesda, MD). For the quantification of FA turnover all FAs of each recorded cell were analyzed and divided into the indicated categories ( 5 independent experiments with at least 3 cells per construct per experiment). Alternatively, cells were recorded every other sec for up to 5 min at $37^{\circ} \mathrm{C}$ in culture medium (buffered with $25 \mathrm{mM}$ HEPES) at the Zeiss Axio Observer $Z 1$, equipped with a TIRF system, using a $\alpha$-Plan Fluar $100 \times / 1.45$ objective with diodelasers $488 \mathrm{~nm}$ and $543 \mathrm{~nm}$ (Zeiss, Bioimaging center (BIC) University of Konstanz). Videos were analyzed with ZEN 2012 (Zeiss) or ImageJ.

\section{Live imaging and analysis of cell motility}

Cells were seeded on $\mu$-dishes (ibidi) coated with FN and grown overnight at $37^{\circ} \mathrm{C}$ and $5 \% \mathrm{CO}_{2}$. Pictures were taken every $30 \mathrm{~s}$ for $1 \mathrm{~h}$ in brightfield with a $40 \times$ objective at $37^{\circ} \mathrm{C}$ and $5 \% \mathrm{CO}_{2}$. Movies and kymographs of lines across the cells were analyzed with Imagej. The speed of movement of the cell edges was measured using the plugin "Kymo Line ROI" (Elisa May, BIC University of Konstanz). 100 cells per cell line were measured in three independent experiments. Statistical analysis was performed using the paired $t$-test.

\section{Biochemical analysis}

To analyze the concentration of specific proteins in shLuc and shR1 HeLa and A431 lines, cells were grown to confluency on plastic cell culture dishes (Greiner). To quantify the phosphorylated proteins, HeLa cells were grown on FN coated glass coverslips and lysed with ice-cold lysis buffer $(20 \mathrm{mM}$ TrisHCl pH $7.5100 \mathrm{mM}$ $\mathrm{NaCl}, 5 \mathrm{mM} \mathrm{MgCl} 22 \mathrm{mM}$ EDTA, 1\% Triton-X-100 and 10\% glycerol) containing HALT protease-phosphatase inhibitor cocktail (Thermo Scientific). The lysed cells (in lysis buffer) were homogenized with a 27G needle. Extracts were centrifuged and the supernatant was boiled at $95^{\circ} \mathrm{C}$ for $5 \mathrm{~min}$. Proteins were separated by SDS-PAGE and transferred to a nitrocellulose membrane by Western blot. Membranes were blocked and analyzed with the corresponding primary and secondary Abs. For the analysis of biotinylated $\beta 1$-integrin, cells were incubated on ice with $1 \mathrm{mg} / \mathrm{ml}$ sulfo-NHS-SS-biotin (Pierce) in PBS for $30 \mathrm{~min}$. Free sulfo-NHS-SS-biotin was quenched by two washes with ice-cold solution, containing $100 \mathrm{mM}$ glycine, $0.1 \mathrm{mM} \mathrm{CaCl}_{2}$ and $1 \mathrm{mM} \mathrm{MgCl}$. Biotinylated proteins from cleared cell extracts, lysed as above, were collected with $25 \mu$ l of streptavidin beads at $4{ }^{\circ} \mathrm{C}$ overnight and analyzed by Western blot with an $\mathrm{Ab}$ against $\beta 1$-integrin. Where indicated, cells were incubated for $5 \mathrm{~h}$ at $37^{\circ} \mathrm{C}$ in normal media supplemented with $10 \mu \mathrm{M}$ cycloheximide to stop protein synthesis prior to biotinylation. Quantification of proteins from Western blots was done with ImageJ.

\section{Rac1-GTP assay}

Lysates were cleared by centrifugation. Protein concentration was measured and adjusted. A small amount of each sample was saved for protein analysis of the input. Lysates were incubated with $10 \mu \mathrm{g}$ of the Rac-Assay-Reagent Pak-1 PBD agarose conjugate (Upstate) at $4{ }^{\circ} \mathrm{C}$ for $1 \mathrm{~h}$. Agarose beads were washed three times with lysis buffer, resuspended in $2 \times$ sample buffer and boiled for $5 \mathrm{~min}$ prior to separation on SDS gels. Proteins were transferred to a nitrocellulose membrane, blocked, incubated with a primary Ab against Rac1 (BD Bioscience) and analyzed as described above.

\section{Quantification of FAs}

HeLa and A431 shLuc and shR1 cells were seeded on FN-coated glass coverslips and fixed after $24 \mathrm{~h}$ incubation at $37^{\circ} \mathrm{C}$ and $5 \%$ $\mathrm{CO}_{2}$. For siRNA treatment, the cells were transfected and seeded after $48 \mathrm{~h}$ onto FN or PLL-coated glass coverslips. After additional $24 \mathrm{~h}$ incubation at $37^{\circ} \mathrm{C}$, cells were fixed. For DNA transfection, shLuc and shR1 cells were seeded $6 \mathrm{~h}$ after transfection to FNcoated coverslips and incubated for $48 \mathrm{~h}$ prior to fixation. Cells were then immunostained with the paxillin $\mathrm{Ab}$ as described above and recorded at the LSM. The number of FAs per cell was counted and the size of each cell was measured with ImageJ. Each experiment was performed at least three times and 100 to 150 cells per construct and experiment were analyzed. The number of FAs per cell in HeLa cells was normalized to the size of the cells $\left(\mu \mathrm{m}^{2}\right)$. In A431 cells, the number of FAs per cell was quantified, since it was already shown that shLuc and shR1 are not different in size (Solis et al., 2012). Statistical analyses were performed as indicated by a paired $t$-test or one-way ANOVA.

\section{Pulse chase experiments with $\beta 1$-integrin $A b$}

Cells grown on FN-coated coverslips were serum starved for $2 \mathrm{~h}$ and incubated with the $12 \mathrm{G} 10 \beta 1$-integrin $\mathrm{Ab}(5 \mu \mathrm{g} / \mathrm{ml})$ in serum free medium for $1 \mathrm{~h}$ at $37^{\circ} \mathrm{C}$. Cells were washed three times with PBS and chased for the indicated times with normal growth medium. After three washes with PBS, cell surface-bound Ab was removed with cold acidic buffer $(0.5 \mathrm{M} \mathrm{NaCl}, 0.2 \mathrm{M}$ acetic acid) for $10 \mathrm{~s}$ followed by three additional washes with cold PBS. Then, cells were fixed with PFA, permeabilized and immunostained as described above. For quantification, the mean fluorescence intensity per cell of combined Z-stacks was determined with Image J from three independent experiments (100-150 cells for each time point, construct and experiment). Statistical analysis was performed with one-way ANOVA.

\section{Drug treatment}

Cells seeded on FN were grown as described above. The cells were then incubated for $1 \mathrm{~h}$ in medium containing $1 \mathrm{mM}$ amiloride or DMSO as control. To analyze and quantify the number of FAs, cells were fixed and treated as described above.

\section{Results}

\section{Reggie-1 knockdown affects FAs}

In HeLa cells, FAs are typically localized at the cell periphery, as exemplified by immunostainings with anti-paxillin Ab (Fig. 1A). In these cells, reggie-1 and reggie- 2 reside at intracellular vesicles and at the plasma membrane (Langhorst et al., 2008b; Solis et al., 2013). Paxillin does not co-localize to any significant extent with reggie-1 and reggie-2 except for small areas where reggie 


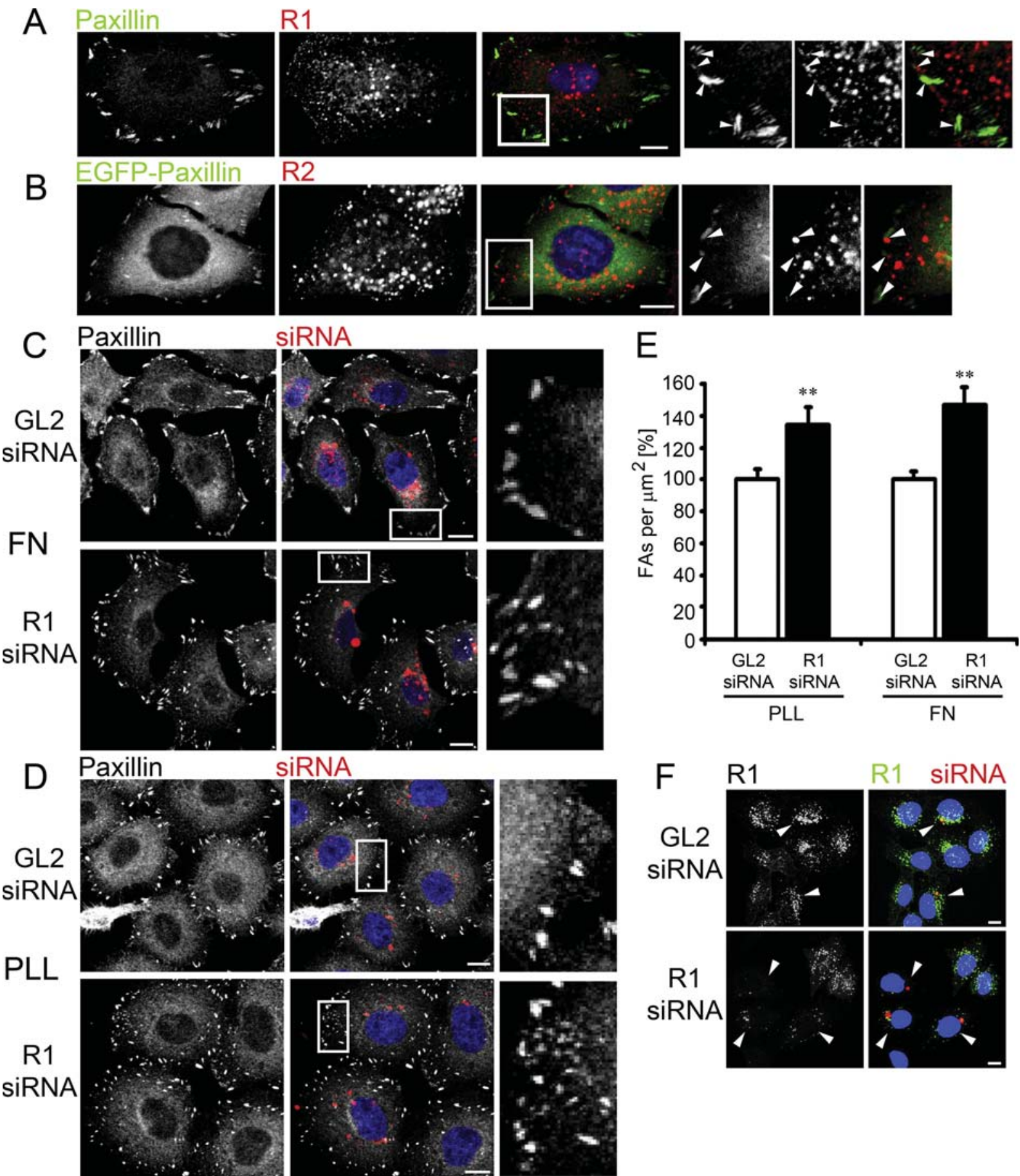

Fig. 1. Reggie-1 siRNA affects the number and distribution of FAs in HeLa cells. (A) Immunostaining of paxillin and reggie-1 (R1) in HeLa cells on fibronectin (FN) shows paxillin in FAs in the cell periphery and R1 in small vesicles and puncta which occasionally co-localize with FAs (arrowheads). The boxed area is enlarged (right). A similar pattern can be observed with EGFP-paxillin and reggie-2 (R2) (B). Reggie-1 siRNA treated cells (labeled siRNA in red) on FN (C) or poly-L-lysin (PLL) (D) have more FAs in a scattered distribution ( $C$ and D lower panels) compared to GL2 siRNA control cells (C and D upper panels). The boxed areas are enlarged (right). (E) Quantification of FAs per $\mu \mathrm{m}^{2}$ showed significantly more FAs in reggie-1 knockdown cells on FN $\left(n=3,{ }^{* *} p<0.01\right.$, paired $t$-test, error bars, SEM) and on PLL $\left(n=4\right.$, ${ }^{* *} p<0.01$, paired $t$-test, error bars, SEM) compared to GL2 controls. Combined z-stacks from immunostaining with an Ab against R1 prove efficient downregulation of reggie-1 by R1 siRNA (red). Cells containing the siRNA are marked by arrowheads (F). All scale bars, $10 \mu \mathrm{m}$. Nuclei are labeled by DAPI (blue).

vesicles seem to partially overlap with paxillin (or EGFP-paxillin) positive FAs (Fig. 1A, B zoom ins). Former results showed that the knockdown of reggie-1 leads to the degradation of reggie2 in HeLa cells (Solis et al., 2007, 2013). To investigate whether the knockdown of reggie- 1 and loss of reggie-2 affects FAs, we treated cells with (AlexaFluor546-labeled) siRNA against reggie-1
(R1) or luciferase (GL2) as control. Immunostainings confirmed the reduction of reggie-1 in siRNA treated cells (Fig. 1F), showing the efficiency of the siRNA. The number and distribution of FAs were determined by the paxillin $\mathrm{Ab}$ (Fig. 1C-E).

R1 siRNA led to a change of FAs on fibronectin (FN) and on poly-L-lysine (PLL) (Fig. 1C and D lower panels): The paxillin 
clusters became disorganized and more widely distributed compared to GL2 siRNA treated and wild type HeLa cells, where FAs resided mainly at the cell periphery (Fig. $1 \mathrm{~A}, \mathrm{C}$ and $\mathrm{D}$ ). To quantify this effect the number of FAs per $\mu \mathrm{m}^{2}$ was determined in reggie-1 siRNA treated and GL2 siRNA control cells. Reggie-1 knockdown led to a $34 \%$ increase in number of FAs on PLL and to a $46 \%$ increase on FN compared to control siRNA treated cells (Fig. 1E).
To substantiate this effect and to explore the underlying mechanisms we used cell lines with stable knockdown of reggie-1 (shR1 cells) (Solis et al., 2012, 2013). Two different shRNA sequences against reggie-1 (shR1.0 and shR1.1) were used to exclude unspecific side effects. The shRNA sequence against luciferase (shLuc) served as control. Immunostainings (Fig. 2A), and Western blots (Fig. 2C) with the reggie-1 Ab showed that shR1.0 and shR1.1 were efficient in downregulating reggie- 1 and both led to the
A

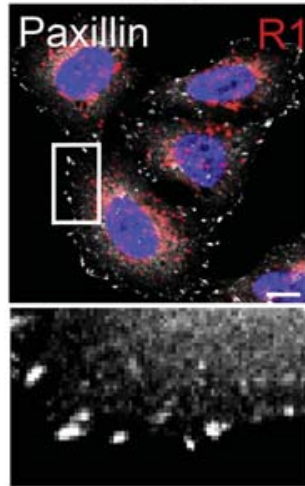

B
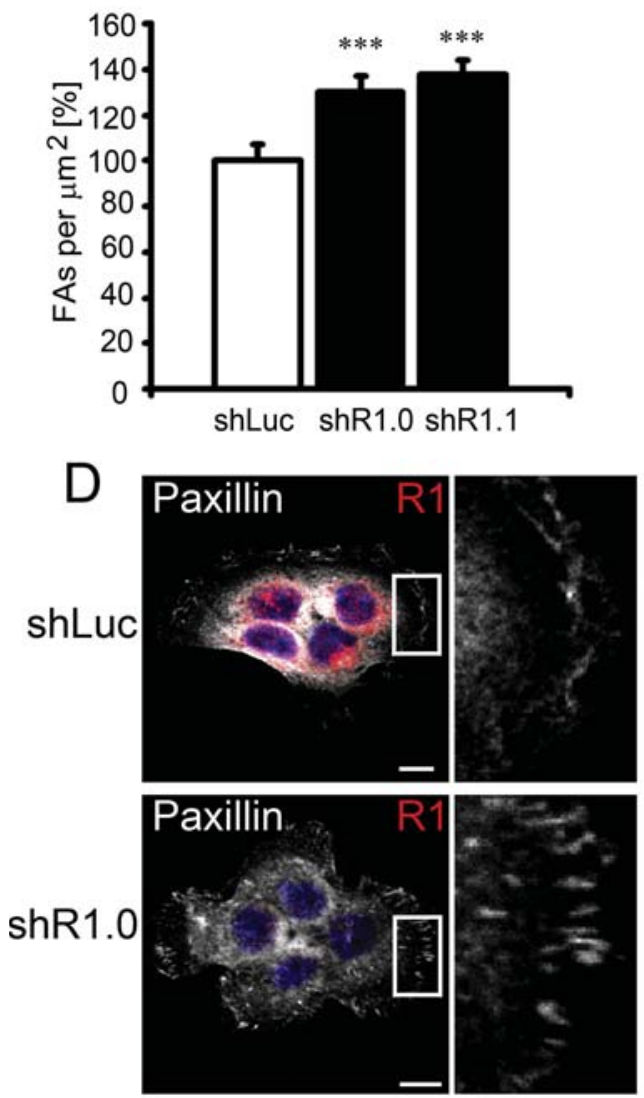

$\operatorname{shR} 1.0$
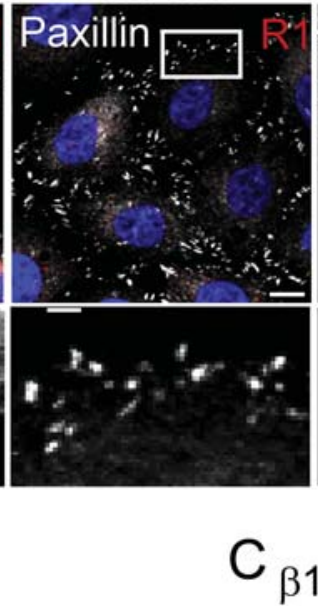

$\operatorname{shR} 1.1$

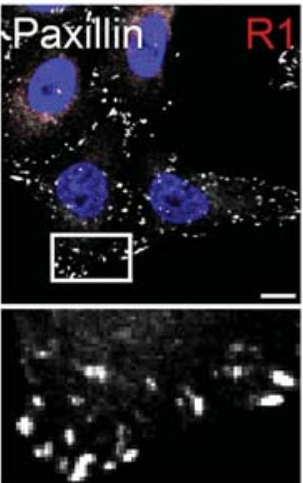

Luc R1.0 R1.1

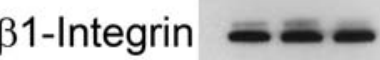

FAK

\section{Paxillin}

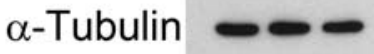

R1

$\mathrm{R} 2$

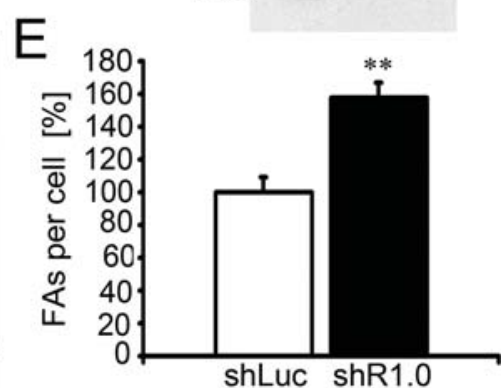

F

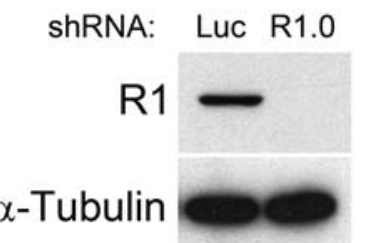

Fig. 2. Stable knockdown of reggie-1 affects FAs in HeLa and A431 cells. (A) HeLa cells on FN stably transfected with shR1.0 and shR1.1 lose most of their reggie-1 specific immunostaining (red). FAs labeled by paxillin (white) were more numerous and scattered in shR1.0 as well as in shR1.1 cells, compared to the shLuc control. Boxed areas are enlarged (below). (B) Quantification of FAs per $\mu \mathrm{m}^{2}$ revealed that shR1.0 and shR1.1 have significantly more FAs than shLuc cells $\left(n=3\right.$, ${ }^{* * *} p<0.001$, one-way ANOVA, error bars, SEM). (C) Western blot analysis of shLuc, shR1.0 and shR1.1 cells show that reggie- 1 was downregulated, which led to a degradation of reggie-2, whereas $\beta 1$-integrin, paxillin and FAK remained unchanged. (D) Paxillin (white) localized in A431 cells on FN predominantly at cell edges and occasionally in FA structures. shR1.0 cells had significantly more paxillin-labeled FAs per cell which were widely scattered and not confined to the periphery. The boxed areas are enlarged (right). Quantification of FA number per cell revealed significantly more FA per cell in shR1.0 cells compared to shLuc cells $\left(n=3,{ }^{* *} p<0.01\right.$, paired $t$-test, error bars, SEM) (E). Reggie-1 downregulation was efficient in shR1.0 cells (F). All scale bars $10 \mu \mathrm{m}$. Nuclei are labeled by DAPI (blue). 
degradation of reggie-2. The paxillin staining in these cells demonstrated that both reggie-1 shRNAs affected FAs to a similar extent as the siRNA against reggie-1: FAs became more numerous, disorganized and scattered in the absence of reggie-1 (Fig. 2A). Similar to the R1 siRNA treated cells, the number of FAs per $\mu \mathrm{m}^{2}$ increased by 30 and 37\%, respectively, in shR1.0 and shR1.1 cells over controls (Fig. 2B). This was not caused by changes in the expression of paxillin, $\beta 1$-integrin or focal adhesion kinase (FAK), as shown by Western blots (Fig. 2C).

To assure that the phenotype after loss of reggie-1 was not confined to HeLa cells, we used A431 cells with either a stable knockdown of reggie-1 (shR1.0) or luciferase (shLuc), seeded these cells on FN and immunostained them with paxillin and reggie-1 (R1) Abs. Staining and Western blots showed efficient downregulation of reggie- 1 in shR1.0 cells (Fig. 2D and F). A431 cells are epithelial cells that, in contrast to HeLa cells, form strong E-cadherin-dependent cell-cell contacts and do not form FAstructures to the same extent as HeLa cells. Paxillin localized in these cells either to ruffles or, to a lower extent, to FAs at the periphery, where the cells were not in contact with one another (Fig. 2D). Reggie-deficient A431 cells had more paxillin-labeled FAs and reduced paxillin in ruffles (Fig. 2D). The number of FAs per cell increased by $56 \%$ in shR1.0 cells compared to shLuc cells (Fig. 2E).

The formation of FAs is integrin-dependent, implying that reggie-1 downregulation might affect integrin trafficking, as previously seen for E-cadherin (Solis et al., 2013). Therefore, we transfected HeLa shLuc and shR1.0 cells (henceforth shR1 cells) with an $\alpha 5$-integrin-EGFP construct and used TIRF microscopy to recognize the protein in FAs in the substrate-near region. This approach showed, that shR1 cells displayed more integrin-EGFPlabeled FAs at the substrate-near membrane than shLuc cells (Fig. 3A), similar to the result obtained with paxillin staining. This effect was also visible, when shLuc and shR1 cells were immunostained live with an Ab against $\beta 1$-integrin (Fig. 3B). To control that these $\beta 1$-integrin-clusters represent FAs, shLuc and shR1 cells were transfected with EGFP-paxillin and stained live against $\beta 1$-integrin. Fig. 3D shows that scattered $\beta 1$-integrin clusters in shR1 cells are indeed positive for the FA-marker paxillin (zoom in). Thus, in the absence of reggie-1, FAs are disorganized as seen with paxillin and $\alpha 5$ and $\beta 1$-integrin.

As an additional control for the specificity of the effect, shR1 cells were transfected with a reggie-1 rescue construct (R1-rescue) which is resistant to the shRNA (Munderloh et al., 2009). The non-rescued cells (Fig. $3 \mathrm{C}$ and box 2) displayed the shR1-FA phenotype showing an increased number and widely scattered paxillin-labeled FAs whereas the rescued cells showed fewer FAs positioned at the cell periphery much as control cells (Fig. $3 \mathrm{C}$ and box 1; for quantification see Fig. $8 \mathrm{H}$ and I). Western blots of shR1 compared to shLuc cells showed no difference in the total level of $\alpha 5$-integrin or in the phosphorylation state of paxillin but a significant increase of phosphorylated (Y576/577) FAK and a band above FAK (Fig. 3E). The expression level of $\alpha 5$-integrin-EGFP is also not different in shLuc and shR1 cells (Fig. 3E lower panels). These data show that the knockdown of reggie-1 led to an increase in FA number, change in shape and scattered distribution, together with increased phosphorylation of FAK, suggesting that reggies are involved in the regulation of FA structure and position.

Reggie-1 downregulation affects plasma membrane movement and spreading

The regulation and turnover of FAs is important for cell motility. Therefore, we asked whether reggie- 1 downregulation and the ensuing change in FA number and distribution would affect membrane motility. shLuc and shR1 cells on FN-coated ibidi $\mu$-dishes were monitored for $1 \mathrm{~h}$ (Movie 1 ). The rate of membrane movement was analyzed by kymographs that were taken for each cell in the visual field (Fig. 4A). The membrane dynamics on both sides of the cell were measured and quantified (Fig. 4A, B). The kymographs and Movie 1 show that shR1 cells move more actively compared to shLuc cells (Fig. 4A arrowheads). A quantification of this movement showed that the membrane in the periphery of shR1 cells moved twice as much as in shLuc cells (Fig. 4B). Thus, the rise of FA number and their abnormal distribution in shR1 cells is linked to enhanced membrane dynamics.

To assess whether the effect of reggie- 1 knockdown might not only affect cell substrate adhesion during steady state but also the early stages of cell-substrate binding, we performed a spreading assay and labeled the cells with phalloidin and paxillin antibody. After $2 \mathrm{~h}$ of spreading on FN both cell lines were spread but shR1 cells were on average about $100 \mu \mathrm{m}^{2}$ smaller than control cells (Fig. 4C, D), in agreement with published data showing an impaired spreading of reggie-1 siRNA treated HeLa cells (Neumann-Giesen et al., 2007). Staining for paxillin revealed that shLuc cells had many large paxillin clusters that were localized preferentially at the periphery of the cells whereas shR1 cells had a less organized pattern of paxillin staining appearing as very small dots (Fig. 4C zoom ins).

\section{Role of Rac1 activation}

Cell movement and spreading are influenced by Rac activity (Nobes and Hall, 1999) and Rac was suggested to contribute to FA regulation through adhesion component stabilization (Steffen et al., 2013). To analyze whether the activation of Rac1 was affected in shR1 cells, we determined the amount of GTP-bound Rac1 by affinity-purification with the Rac1-binding protein Pak1-PBD, bound to agarose. Indeed, while both shLuc and shR1 cells had similar amounts of total Rac1 (Input), shR1 cells had twice as much Rac1-GTP than shLuc cells (Fig. 4E). Therefore, we used the Rac1 blocker amiloride (Koivusalo et al., 2010) to assess whether Rac1 inhibition can change the effect of reggie- 1 knockdown on FAs. The number of FAs in shR1 cells (but not in shLuc cells) was reduced to near normal, when cells were treated for $1 \mathrm{~h}$ with amiloride (Fig. 4F, G). Treatment of shLuc and shR1 cells with DMSO as control showed the typical increase in number of FAs in shR1, compared to shLuc cells. Thus, reggies contribute to the control of the activation of Rac1 which is connected to the control of FA number and distribution.

Rac activity was implicated in vesicle trafficking and Rac itself was implied to be subjected to recycling to the plasma membrane during cell migration (Palamidessi et al., 2008). This and the notion that FA turnover is strongly dependent on vesicle trafficking and integrin delivery (Bridgewater et al., 2012), led us to ask, whether and how reggies might affect FA turnover and integrin trafficking and recycling.

\section{Reggie-1 traffics together with $\alpha 5$ - and $\beta 1$-integrin}

To corroborate that reggie-1 regulates FA turnover through its influence on integrin trafficking and recycling, we co-transfected HeLa cells with reggie-1 coupled to mRFP (R1-RFP) and either $\alpha 5$-integrin-EGFP or $\beta 1$-integrin-EGFP, because $\alpha 5 \beta 1$-integrin is a receptor for FN. Recordings of moving vesicles with the Colibri system revealed that R1-RFP at vesicles move together with $\beta 1$-integrin, as well as with $\alpha 5$-integrin (Fig. $5 \mathrm{~A}, \mathrm{~B}$ and Movie 2).

We were interested in co-trafficking of reggie- 1 and integrins at the plane of FAs and therefore used TIRF microscopy on living cells to observe integrin trafficking at the substrate-near region. The movies showed that $\beta 1$-integrin-EGFP (Fig. 6A, Movie 3) as 


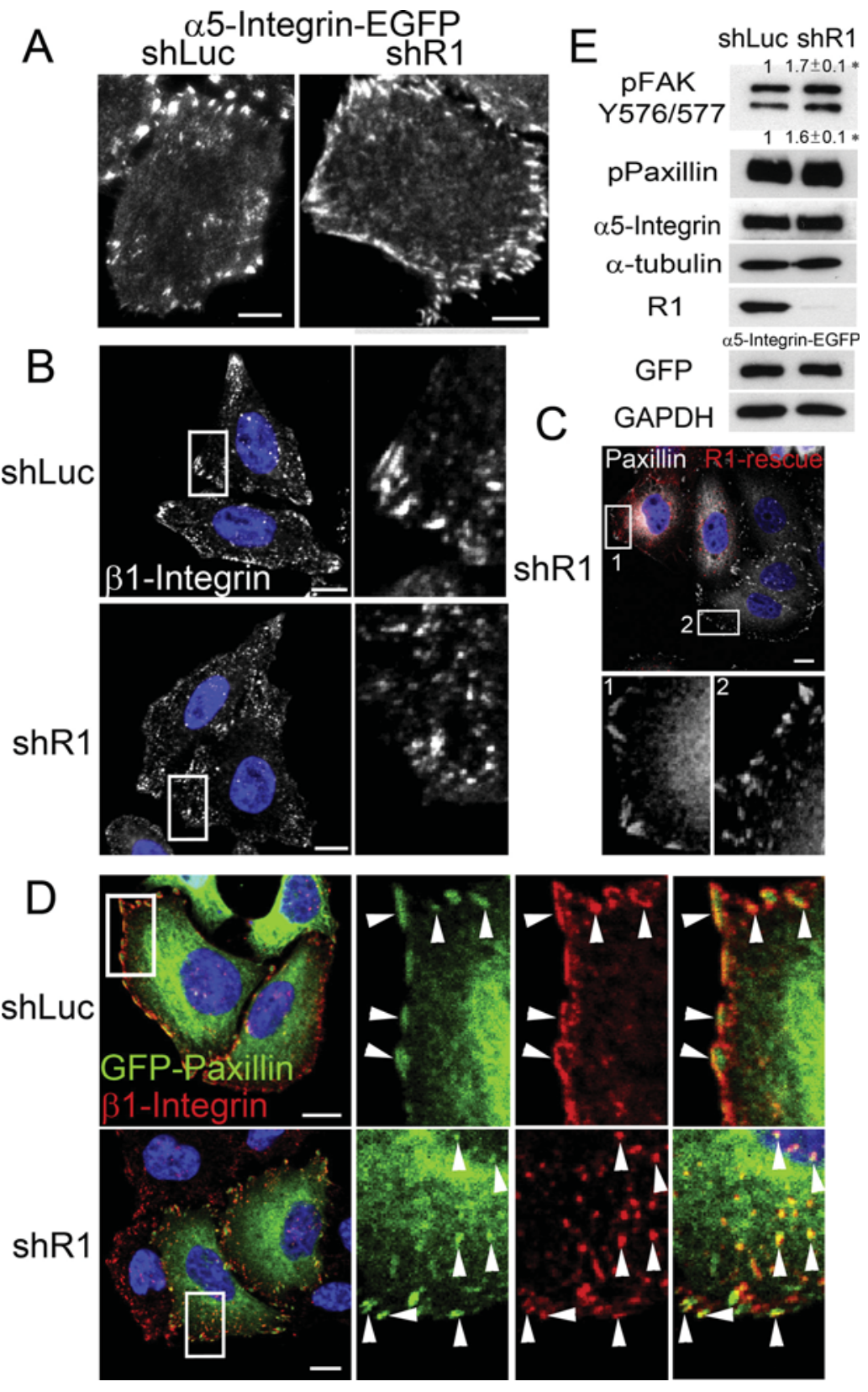

Fig. 3. Reggie- 1 knockdown affects the distribution of $\alpha 5$ - and $\beta 1$-integrins and FAK phosphorylation. (A) TIRF images of overexpressed $\alpha 5$-integrin-EGFP in HeLa shLuc and shR1 cells on FN show more FAs in shR1 cells. $\beta 1$-integrin live immunostaining shows its localization at the membrane. In shLuc cells FAs preferentially reside at the periphery, while shR1 cells show a scattered distribution of integrin staining (B). Boxed areas are enlarged (right). shR1 cells had more and scattered FAs compared to shLuc cells. shR1 cells were transfected with a R1-rescue (shRNA insensitive) construct (Reggie-1-EGFP-rescue, shown in red) and immunostained with a paxillin Ab (white). The boxed areas are enlarged ( 1 and 2 below) showing FAs in transfected (1) and untransfected (2) cells (C). The increase of FA number was also visible in shLuc and shR1 cells overexpressing GFP-Paxillin and stained (live) with a $\beta 1$-integrin Ab. The boxed areas are enlarged (right) and $\beta 1$-integrin clusters are positive for the FA marker paxillin (arrowheads) (D). All scale bars, $10 \mu \mathrm{m}$. Nuclei are labeled with DAPI (blue). (E) shLuc and shR1 cells grown on FN showed no differences in total $\alpha 5$-integrin levels and paxillin phosphorylation (pPaxillin) but the phosphorylation of FAK at Y576/577 in shR1 cells was increased. $\left(n=5, \pm\right.$ SEM, ${ }^{*} p<0.05$, paired $t$-test). Transfected shLuc and shR1 cells showed no difference in the expression level of $\alpha 5$-integrin-EGFP.

well as $\alpha 5$-integrin-EGFP (Fig. 6B, Movie 4) are localized in FAs at the periphery (Fig. 6A and B zoom ins, upper panels), as well as in moving vesicles. Vesicles had both R1-RFP and $\alpha 5$-integrin-EGFP or R1-RFP and $\beta 1$-integrin-EGFP, respectively (Fig. 6A, B and Movie 3 and 4). When FAs were identified with EGFP-paxillin in cells cotransfected with R1-RFP, paxillin clustered at FAs but was not seen in moving vesicles with reggie-1. However, R1-RFP vesicles often contacted in a "kiss-and-run mode" the EGFP-paxillin labeled FAs (as shown in Fig. 6C and Movie 5).
Thus R1-RFP vesicles contact paxillin-positive FAs, and reggie1 co-traffics with $\alpha 5$ - and $\beta 1$-integrin-EGFP in vesicles, suggesting an involvement of reggie-1 in integrin-dependent FA formation and remodeling.

Reggie-1 downregulation affects the turnover of FAs

FAs are subject of constant remodeling and turnover (Bridgewater et al., 2012). To determine whether the turnover 

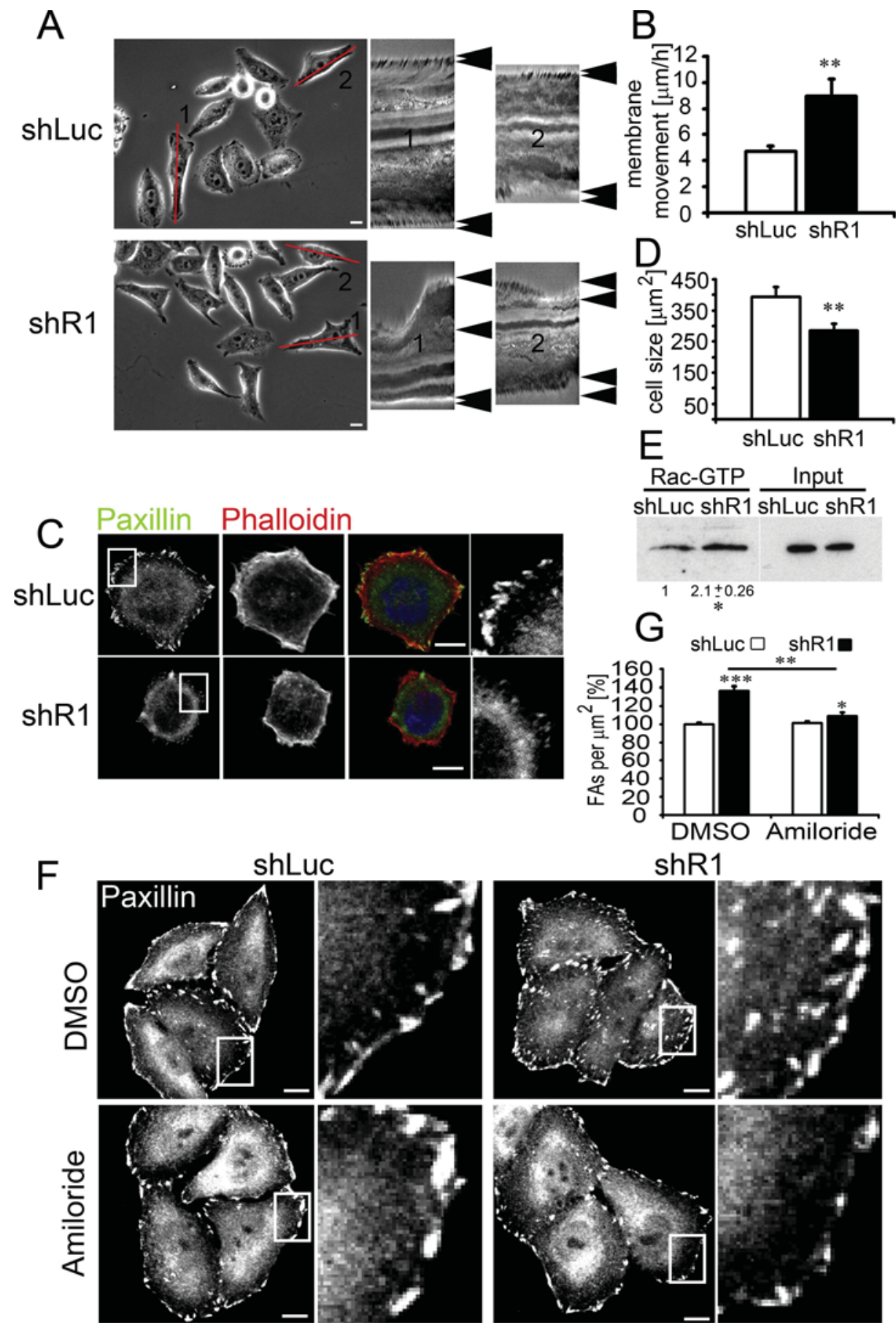

Fig. 4. Reggie-1 affects membrane dynamics, spreading and Rac1 activation. Live imaging in $30 \mathrm{~s}$ intervals (under brightfield) for $1 \mathrm{~h}$ shows that shR1 cells move more than shLuc cells (A) (Movie 1). The right panels show kymographs of the regions 1 and 2, marked by the red lines. The arrowheads indicate the extent of membrane dynamics of the two cells over $60 \mathrm{~min}$. The membrane motility of shR1 cells is higher compared to shLuc cells (B) $\left(n=3,{ }^{* *} p<0.01\right.$, paired $t$-test, error bars, SEM).(C) Spreading assay with shLuc and shR1 cells for $2 \mathrm{~h}$ on FN. shR1 cells are smaller and show less organized paxillin clusters, compared to control cells. Boxed areas are enlarged. (D) Quantification of the cell size after $2 \mathrm{~h}$ of spreading $\left(n=3,{ }^{* *} p<0.01\right.$, paired $t$-test, error bars, SEM). (E) Rac1 is overactivated in shR1 cells (Rac-GTP assay), whereas total Rac1 is equal in shLuc and shR1 cells (input). Rac1-GTP was (twofold) increased in shR1 cells (lanes 1 and 2$)\left(n=3, \pm \mathrm{SEM},{ }^{*} p<0.05\right.$, paired $t$-test). (F and G) In shLuc and shR1 cells, treated with the Rac1 inhibitor amiloride for $1 \mathrm{~h}$, the number and localization of FAs was restored to values observed in shLuc cells (F). Boxed areas are enlarged (right). Quantification of FAs per $\mu \mathrm{m}^{2}$, revealed significantly fewer FAs in shR1 cells with amiloride than in DMSO treated shR1 cells $(\mathrm{G})\left(n=3,{ }^{* * *} p<0.001,{ }^{* *} p<0.01,{ }^{*} p<0.05\right.$ one-way ANOVA, error bars, SEM). All scale bars $10 \mu \mathrm{m}$.

and remodeling of FAs depends on reggie-1, we monitored the EGFP-paxillin labeled FAs in shLuc and shR1 cells on FN for $1 \mathrm{~h}$. For all FAs of each recorded cell, we analyzed, whether they were stable (Fig. 7A; red arrows), newly formed and/or elongating (blue arrows), or disappearing and/or retracting (green arrows) (Table 1 ,
Fig. 7A and Movie 6). There were significantly more EGFP-paxillin labeled FAs per $\mu \mathrm{m}^{2}$ in shR1 than in shLuc cells (Table 1). In addition, shR1 cells showed significantly more stable, as well as higher numbers of disappearing and/or retracting FAs. The number of newly formed and/or elongating FAs was also increased, even 


\section{A B1-Integrin-EGFP}

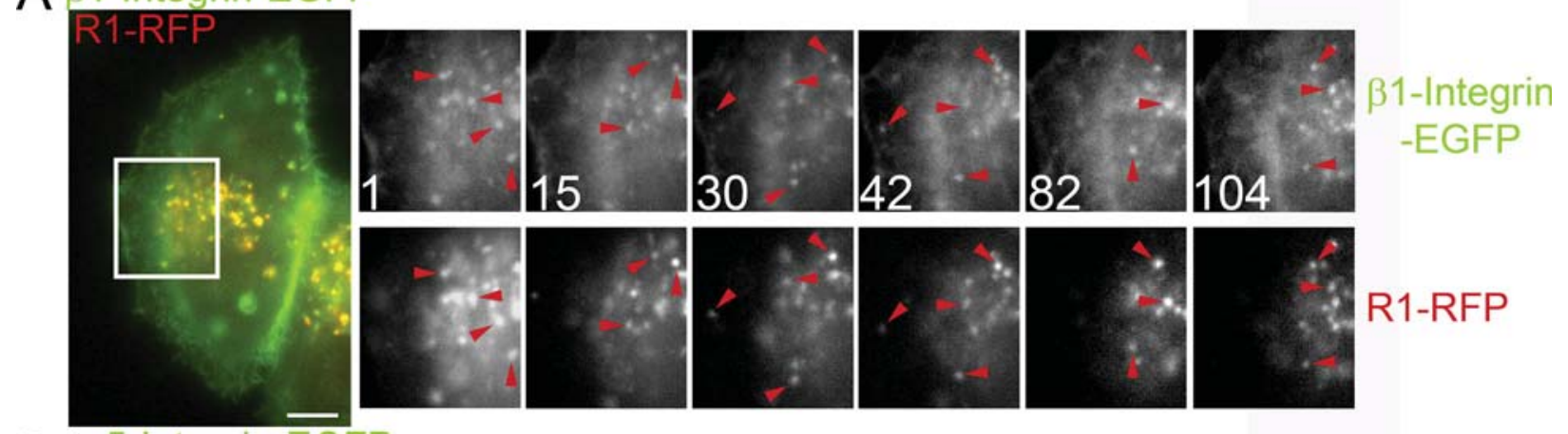

$\mathrm{B}$

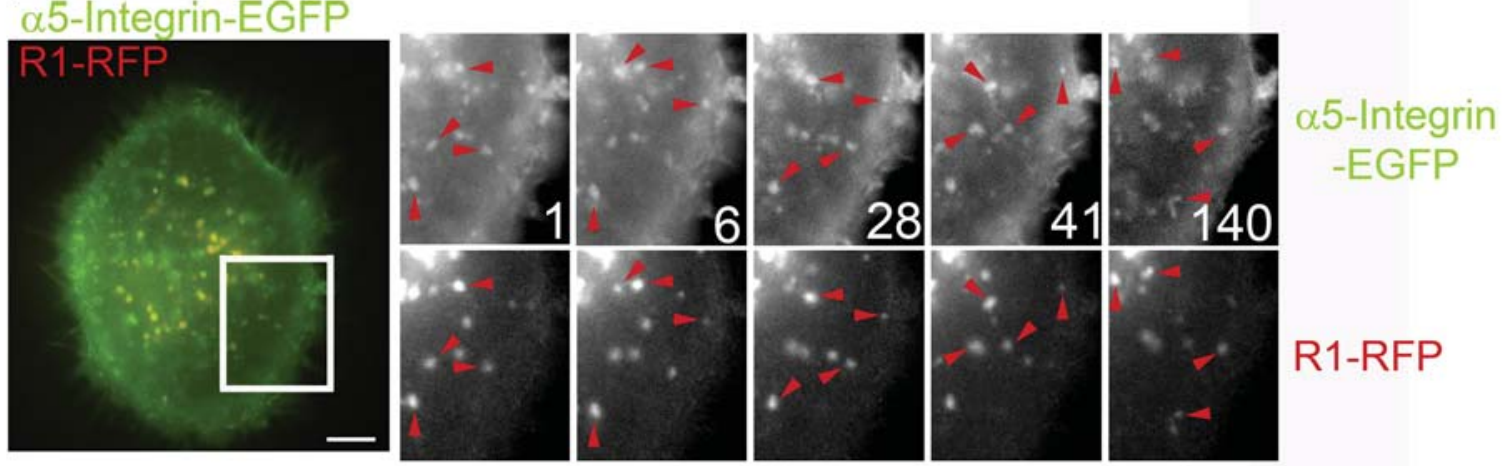

Fig. 5. Co-trafficking of reggie-1 with $\alpha 5$-integrin and $\beta 1$-integrin. Live imaging of HeLa cells on FN, transfected with R1-RFP and $\beta 1$-integrin-EGFP (A) or R1-RFP and $\alpha 5$-integrin-EGFP (B). Vesicle trafficking was recorded in $1 \mathrm{~s}$ intervals over $5 \mathrm{~min}$ with a Colibri system. The boxed areas are enlarged (right) and show timelines (in seconds) of moving vesicles in the red and green channels separately. Arrows point to vesicle containing both R1-RFP and $\beta 1$-integrin-EGFP (A) or R1-RFP and $\alpha 5$-integrin-EGFP (B). Scale bars, $10 \mu \mathrm{m}$. The figure corresponds to Movie 2 .
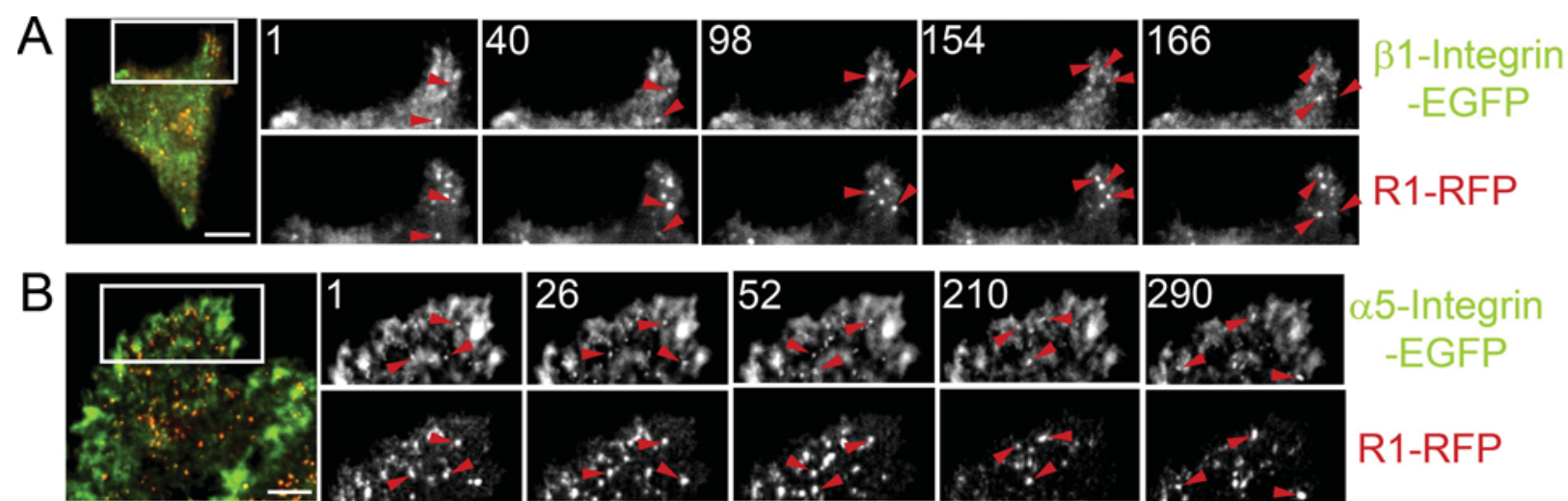
a5-Integrin -EGFP

$\mathrm{C}$
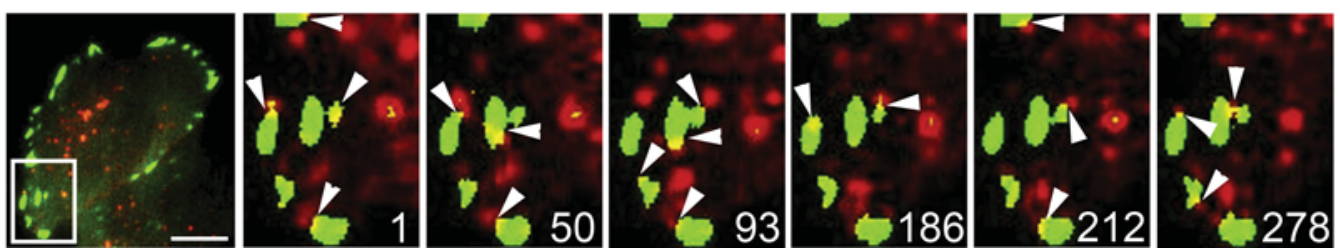

R1-RFP

Fig. 6. Reggie-1 and integrins co-traffic in the substrate-near region and contact FAs. Live imaging of HeLa cells on FN transfected with R1-RFP and $\beta 1$-integrin-EGFP (A), R1-RFP and $\alpha 5$-integrin-EGFP (B) or R1-RFP and GFP-Paxillin (C). Vesicle trafficking was recorded in $2 \mathrm{~s}$ intervals up to 5 min. The boxed areas are enlarged (A, B and C to the right) and timelines (in seconds) of the red and green channels are shown separately (A and B). Examples of vesicles containing R1-RFP together with $\beta 1$-integrin-EGFP (A) or R1-RFP together with $\alpha 5$-integrin-EGFP (B) are marked by arrowheads. GFP-Paxillin (which is not at vesicles) demarcates FAs (C). The timeline shows R1-RFP vesicles that contact or overlap (arrowheads) with FAs (green, thresholded image). Scale bars, $10 \mu \mathrm{m}$. (A) corresponds to Movie 3, (B) to Movie 4 and (C) to Movie 5. (For interpretation of the references to color in this figure legend, the reader is referred to the web version of this article.)

though this was not significant, probably because of the small sample size (Table 1 ). Cells with knockdown of reggie-1 show a higher extent of FA remodeling, compared to shLuc cells (Fig. 7A, Movie 6). Thus, reggie-1 seems to influence both FA number and remodeling.
Reggies regulate integrin recycling

To determine whether reggie- 1 influences $\beta 1$-integrin trafficking, we conducted a pulse chase experiment in shLuc and shR1 cells. Cells were incubated with the $\beta 1$-integrin Ab $12 \mathrm{G} 10$ for $1 \mathrm{~h}$ 


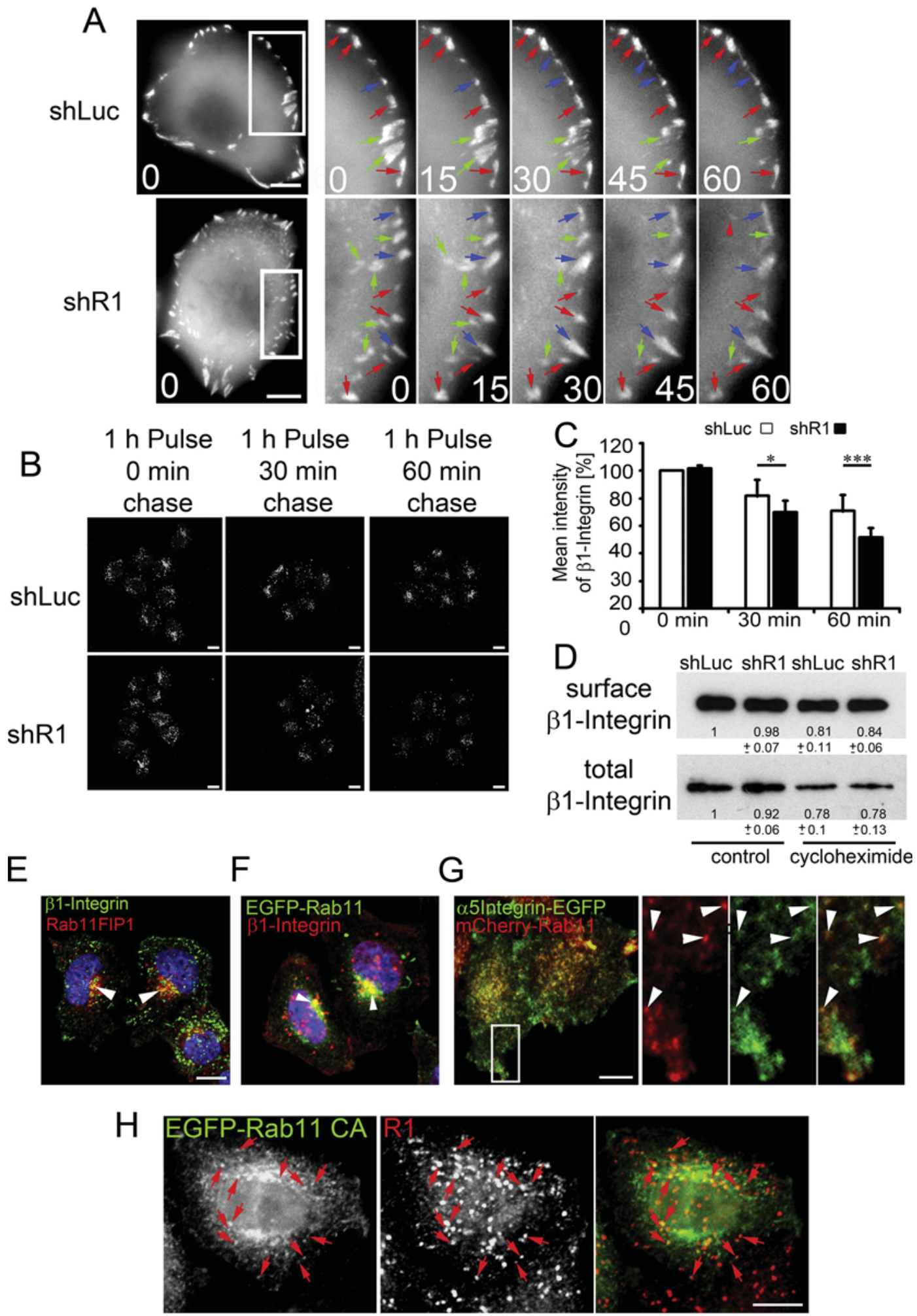

Fig. 7. Reggie knockdown affects FA turnover and integrin trafficking. Live imaging of HeLa shLuc (upper panel) and shR1 cells (lower panel) transfected with GFP-Paxillin on FN (A). Cells were recorded for 60 min and pictures were taken every $30 \mathrm{~s}$. Images to the left show FAs in shLuc and shR1 cells at time 0 (beginning of the recording). The boxed areas are enlarged (right) and timelines (in seconds) are shown. Stable FAs are marked by red arrows, emerging and/or elongating FAs by blue arrows and retracting and/or disappearing FAs by green arrows. The remodeling of FAs in shR1 cells is higher, compared to shLuc cells. The figure corresponds to Movie 6. (B) Pulse chase experiment with a $\beta 1$-integrin $\mathrm{Ab}$ (12G10). shLuc and shR1 cells endocytosed the same amount of Ab after the pulse ( 0 min). Ab labeling in z-stacks disappeared faster in shR1 compared to shLuc cells as quantified in (C) $\left(n=4,{ }^{*} p<0.05,{ }^{* * *} p<0.001\right.$, one-way ANOVA; error bars, SEM). The signal of shLuc cells after $1 \mathrm{~h}$ pulse ( 0 min) was set to $100 \%$. (D) Total $\beta 1$-integrin (lower panel) and surface levels (upper panel) do not differ in shLuc and shR1 cells, as shown in a biotinylation experiment in control cells and after blockage of protein synthesis with cycloheximide ( $n=3 \pm$ SEM). (E) Ab against $\beta 1$-integrin added to live HeLa cells for $1 \mathrm{~h}$ at $37^{\circ} \mathrm{C}$ co-localized with Rab11FIP1 and with EGFP-Rab11a wt (F) at the perinuclear recycling compartment. $(G)$ HeLa cells transfected with $\alpha 5$-integrin-EGFP and mCherry-Rab11a showed co-localization (arrowheads) in the substrate-near region (TIRF images). The boxed area is enlarged (right). (H) EGFP-Rab11a CA co-localized with endogenous reggie-1 (R1) in various vesicles (arrows). All scale bars, $10 \mu \mathrm{m}$. The nuclei are labeled with DAPI. 
Table 1

Quantification of FA tunover.

\begin{tabular}{|c|c|c|c|c|c|c|c|}
\hline \multicolumn{2}{|l|}{ Number of FAs } & \multicolumn{2}{|c|}{ Appearing and/or elongating FAs } & \multicolumn{2}{|c|}{ Disappearing and/or retracting FAs } & \multicolumn{2}{|l|}{ Stable FAs } \\
\hline shLuc & $\operatorname{shR} 1$ & shLuc & shR1 & shLuc & shR1 & shLuc & $\operatorname{shR} 1$ \\
\hline $0.031 \pm 0.0048$ & $0.050 \pm 0.0013^{* *}$ & $0.0145 \pm 0.0043$ & $0.0173 \pm 0.0046$ & $0.0126 \pm 0.0027$ & $0.0210 \pm 0.0032^{* *}$ & $0.010 \pm 0.0013$ & $0.0186 \pm 0.0054$ \\
\hline
\end{tabular}

FAs per $\mu \mathrm{m}^{2} ;{ }^{*} p<0.05 ;{ }^{* *} p<0.01$.

HeLa shLuc and shR1 cells were transfected with EGFP-Paxillin and all FAs were monitored over $1 \mathrm{~h}$ and divided into the three categories. shR1 cells revealed significantly more stable and disappearing and/or retracting FAs and tended to have more appearing and/or elongating FAs $\mu \mathrm{m}^{2}$. The total number of FAs was also enhanced in shR1 cells, compared to the control, as seen before $\left(n=5,{ }^{* *} p<0.01,{ }^{*} p<0.05\right.$, paired $t$-test, mean, \pm SEM).

at $37^{\circ} \mathrm{C}$ in serum free medium, followed by 30 or 60 min chase in normal growth medium and an acidic wash to remove all externally bound Ab (Fig. 7B). After $1 \mathrm{~h}$ pulse $\beta 1$-integrin Ab was seen in small vesicles and to a larger extent in the perinuclear recycling compartment of shLuc and shR1 cells. Fluorescence intensity measurements of whole cell stacks showed that there was no difference between control and reggie-1 deficient cells after $1 \mathrm{~h}$ pulse (Fig. 7C). However, after 30 and 60 min chase, shLuc cells retained more $\beta 1$-integrin $\mathrm{Ab}$ labeling than shR1 cells (Fig. 7B, C), indicating faster recycling of $\beta 1$-integrin in reggie-depleted cells. To exclude that different cell-surface levels of $\beta 1$-integrin might be responsible for the differences in recycling, cell-surface $\beta 1$-integrin was biotinylated under normal growth conditions as well as under cycloheximide treatment to block protein synthesis. The surface levels of $\beta 1$-integrin in shLuc and shR1 cells were not significantly different under both conditions (Fig. 7D). In addition there was no enhanced degradation of $\beta 1$-integrin in shR1 cells, as total $\beta 1$ integrin was similar in shLuc and shR1 cells with and without cycloheximide treatment (Fig. 7D lower panel). Altogether, these results indicate that knockdown of reggie- 1 affects $\beta 1$-integrin recycling without affecting $\beta 1$-integrin membrane expression and degradation.

\section{Reggie-1 controls the number of FAs via Rab11a}

Reggie-1 interacts with Rab11a and is involved in recycling of E-cadherin and the transferrin receptor (Solis et al., 2013) so that reggies might as well play a role in Rab11-dependent integrin recycling. Indeed $\alpha 5$ - and $\beta 1$-integrins co-localize with Rab11a and Rab11FiP1 (also known as Rab coupling protein, RCP) (Fig. 7E-G). Following exposure of living cells to the activating $\beta 1$-integrin $\mathrm{Ab}$ for $1 \mathrm{~h}$ at $37^{\circ} \mathrm{C}$, labeling was concentrated in the recycling compartment together with Rab11FIP1 and EGFP-Rab11a, respectively (Fig. 7E, F). When $\alpha 5$-integrin-EGFP was co-transfected together with mCherry-Rab11a, they co-localized in vesicles close to the substrate-near region of the cell, as seen by TIRF microscopy (Fig. 7G). According to previous results, in which reggie was shown to interact with Rab11a and to regulate its activity (Solis et al., 2013), overexpressed EGFP-Rab11a CA in parental HeLa cells was located primarily at vesicles in the perinuclear region and in the cell periphery (Fig. 7H). Many of the vesicles with EGFP-Rab11a CA were also labeled by a reggie-1 Ab (Fig. $7 \mathrm{H}$ ).

To determine whether the overexpression of Rab11a wt, the Rab11a CA and DN forms might affect the number of FAs in shLuc and shR1 cells, we transfected the cells with the constructs and stained for paxillin. mRFP-C1 served as a control vector. As expected, transfection with the control vector resulted in the normal number of FAs in shLuc cells and in the abnormal pattern and higher number, described above in reggie-deficient cells (Fig. $8 \mathrm{~A}$, I). However, transfection with the Rab11a wt construct as well as the Rab11a CA mutant significantly reduced the number of FAs in reggie-1-deficient cells but had no visible effect on the number of FAs in control cells (Fig. 8B, C, I). A rescue of the phenotype in shR1 cells could also be achieved with a shRNA insensitive reggie-1 construct, showing the specificity of the effect of reggie-1 knockdown (Fig. 8H, I). By contrast, transfection of shLuc cells with the Rab11a DN mutant increased the number of FAs significantly in shLuc cells, but it had no effect on the FAs in shR1 cells (Fig. 8D, I). Integrins are known to be recycled through Rab11-, Rab8- and Rab4-dependent pathways (Bridgewater et al., 2012; Margadant et al., 2011; Sharma et al., 2009). To find an explanation why FA turnover and recycling of integrins in shR1 cells are increased (as shown in Fig. 7) even though Rab11a activity is impaired, we examined if Rab4a or Rab8a-dependent recycling might compensate the reduced activation of Rab11a. shLuc and shR1 cells were transfected with either Rab4a wt, Rab4a DN or Rab8a wt constructs and the number of FAs was quantified (Fig. 8E-I). Indeed, overexpression of Rab4a wt led to an increase in number of FAs in shLuc cells mimicking the phenotype observed in shR1 cells, whereas it did not further increase FA number in shR1 cells (Fig. 8E, I). On the other hand Rab8a wt overexpression did not show any effect (Fig. 8G, I). Interestingly, the Rab4a DN construct rescued the number of FAs in shR1 cells and slightly elevated the number of FAs in control shLuc cells (Fig. 8F, I).

Thus, Rab11a wt and CA constructs rescued the reggie-1 knockdown phenotype, whereas the Rab11a DN mutant caused shLuc cells to acquire the phenotype of reggie- 1 knockdown cells. This is in line with our previous data, where the same mutants rescued and, respectively mimicked the effect of reggie-1 knockdown on E-cadherin recycling (Solis et al., 2013). This is consistent with the interaction of reggie-1 and Rab11a and emphasizes their shared role in recycling of $\alpha 5 \beta 1$-integrin.

\section{Discussion}

The reggie proteins reside at the plasma membrane and at vesicular carriers involved in membrane protein trafficking (Stuermer, 2010) and function in Rab11a-dependent cargo recycling and delivery to specific sites. This function promotes, according to our earlier work, proper E-cadherin recycling, cell adhesion and adherens junction turnover (Solis et al., 2012, 2013) while reggie-1 downregulation impairs cell adhesion. Our present results substantiate the role of reggies in membrane protein recycling and demonstrate that reggies function in Rab11a-controlled and FA-directed trafficking of $\alpha 5$ - and $\beta 1$-integrin. Concretely, using paxillin to visualize FAs, we show in reggie-deficient cells that FAs increased in number, lost their preferential accumulation in the periphery and acquired a scattered distribution.

Moreover, reggie downregulation enhanced the dynamic turnover of FAs and increased membrane dynamics coincident with an elevation of FAK and Rac1 activity (Rac1-GTP). In contrast to views implying reggies in lipid raft-mediated endocytosis (Ait-Slimane et al., 2009; Payne et al., 2007), reggie-deficient cells showed no difference in Ab-labeled $\beta 1$-integrin internalization in a pulse chase assay, but lost the labeling faster than reggieexpressing shLuc control cells. Notably, the specific defects that resulted from loss of reggie-1, such as increase in FA number and a dispersed distribution, were rescued by increased Rab11a 


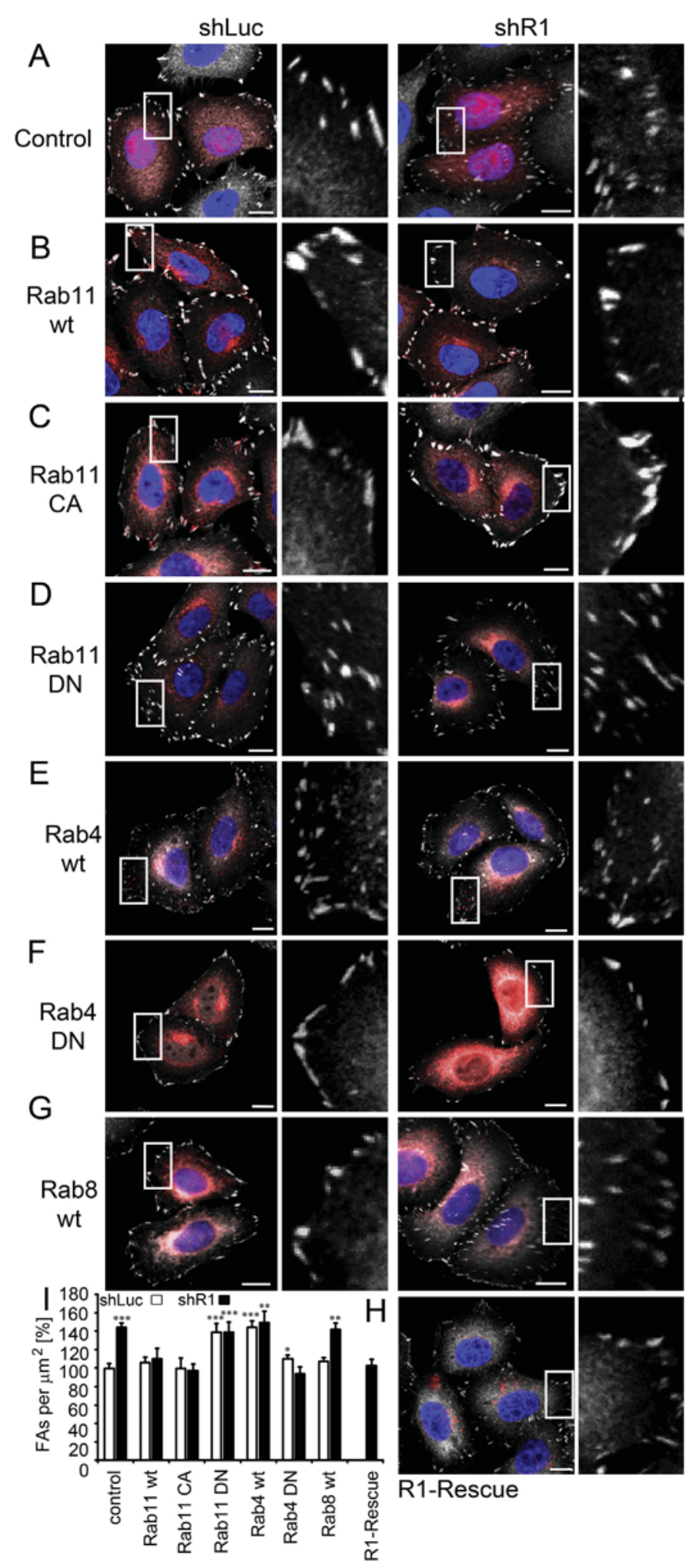

Fig. 8. The FA phenotype after reggie-1 downregulation is cross-rescued by Rab11a. Different Rab-constructs were overexpressed (shown in red) in HeLa shLuc and shR1 cells (A-G). FAs are marked by paxillin (white). Transfection with an mRFP-C1 (control) construct did not affect the FAs in either shLuc or shR1 cells (A). shR1 cells had still more and scattered FAs. Transfection with mCherry-Rab11a (Rab11 wt) had no effect on the number of FAs in shLuc cells (left) but reduced the number of FAs in shR1 cells (right) and changed their distribution (B). An mRFP-Rab11a-CA (Rab11 CA) construct did not affect FAs in shLuc cells, but restored in shR1 cells the number of FAs to control levels (C). mRFP-Rab11a-DN mutant (Rab11 DN) increased the number of FAs in shLuc cells but not in shR1 cells (D). An EGFP-Rab4a construct (Rab4 wt, shown in red) also increased the number of FAs in control cells (E). An ECFP-Rab4a-DN construct (Rab4 DN, shown in red) slightly elevated the number of FAs in shLuc cells and reduced the number of FAs in shR1 cells back to control level (F). Overexpression of mRFP-Rab8a wt (Rab8 wt) did not have an effect on the number of FAs in shLuc or shR1 cells ( $G$ ). The reggie-1-EGFP rescue construct (R1-rescue, shown in red) restored the number of FAs in shR1 cells to control values (H). Quantification of the number of FAs per $\mu m^{2}$ (I) of shLuc and shR1 cells transfected as described above revealed that the Rab11 wt, Rab11 CA, Rab4 DN and R1-Rescue constructs were able to rescue the phenotype in shR1 cells. Rab11 DN and Rab4 wt mimicked the effect of reggie-1 knockdown on FAs in shLuc cells (I) $\left(n=3,{ }^{* * *} p<0.001,{ }^{* *} p<0.01,{ }^{*} p<0.05\right.$, one-way ANOVA, error bars, SEM). 
activity in reggie-deficient cells, transfected with wt or CA Rab11a constructs. Vice versa, DN Rab11a produced in shLuc control cells the reggie-deficiency phenotype: more FAs and scattered distribution.

The downregulation of reggie- 1 and the ensuing disturbances of Rab11 activation resulted in faster turnover of FAs and integrins, evidently by a compensatory activation of the Rab4 dependent fast recycling pathway. Increased Rab4 expression induced, like reggie downregulation, more FAs. Reggie interacts with Rab11a but apparently not with Rab4 (Solis et al., 2013), which indicates an indirect role of reggie in the modulation of the Rab4 pathway. It was shown previously that SNX4 tubulation is important during Rab4 to Rab11 endosomal transition (van Weering et al., 2012). The ability of reggie to bind simultaneously to Rab11a and SNX4 (Solis et al., 2013) might lead to an enhanced retention of $\beta 1$-integrin and other membrane proteins in the Rab4-positive "fast-recycling" pathway. This would account for the fact that the surface levels of membrane cargo ( $\beta 1$-integrin, E-cadherin, Transferrin receptor) remain unaffected in shR1 cells (Solis et al., 2013), despite of the impaired Rab11a dependent recycling process.

\section{Reggie in vesicle trafficking}

Observation of live cells overexpressing fluorescently tagged proteins with TIRF microscopy showed that reggie- 1 co-traffics with both $\alpha 5$ - and $\beta 1$-integrin vesicles which engage in kiss-andrun contacts with FAs, implying a reggie and Rab11-dependent delivery of integrins to FAs. Altogether, these data suggest that reggie-1, in concert with Rab11 and controlled Rac1 and FAK activation, coordinate the targeted recycling of $\alpha 5$ - and $\beta 1$-integrins to cell-substrate contacts and thereby regulate FA formation and cell-substrate adhesion.

Since reggies are attached to membranes it is conceivable that reggies act as specific vesicle coats and "guide" vesicular carriers with specific membrane proteins to their target sites at the plasma membrane. This function would account for the fact that reggies were implicated in trafficking of different membrane proteins and in different cells (Stuermer, 2010). In fact, there is no cell type without reggie, and they show a striking degree of evolutionary conservation (Rivera-Milla et al., 2006).

The observation of reggie-dependent cargo trafficking has been considered as reggie/flotillin-dependent and lipid raft bound endocytosis (Glebov et al., 2006). Our present assay with a $\beta 1$-integrin antibody as well as earlier experiments with E-cadherin, transferrin receptor and the T-cell receptor did not detect a reggie-mediated endocytosis but discovered instead a reggie-assisted Rab11adependent recycling route (Solis et al., 2012, 2013; Stuermer, 2010).

\section{Influence of reggie on FAK, Rac1 and Rab11 activation}

In a wound closure assay, reggie-deficient A431 cells migrated faster, probably because reggies influence many signaling molecules resulting in the imbalanced activation of Rho-GTPases after reggie downregulation (Solis et al., 2012). The increased membrane motility in the present reggie-deficient HeLa cells correlates with increased FAK and Rac1 activation and abnormal FAs. It is possible that the effect of reggie-1 downregulation on Rac1 activation results from abnormal vesicle transport which seems to be normally governed by reggie and Rab11a. This implies that the delivery of Rac1 to specific regions in the cell occurs through its transport at vesicles in HeLa cells (Palamidessi et al., 2008).This affects the phosphoinositide composition of the transport vesicles and increases the preference of Rac1 for lipid rafts (Balasubramanian et al., 2007), which are the microdomains favored by reggies. Rac1 and Rab11 have been shown to interact genetically in Drosophila (Assaker et al.,
2010). Recently, Emery and Ramel have suggested that Rab11 is involved in the spatiotemporal regulation of Rac activity during collective cell movement during Drosophila oogenesis (Emery and Ramel, 2013; Ramel et al., 2013) and Rab11FIP3, which binds Arf6, can regulate polarized Rac1 activation in HeLa cells (Jing et al., 2009). These reports together with our data indicate that reggie and Rab11 might regulate Rac1 recruitment and its spatially confined activation. A role of Rac in paxillin turnover in FAs in mouse embryonic fibroblasts has also been suggested (Steffen et al., 2013). Moreover, RCP/Rab11-driven recycling of $\alpha 5 \beta 1$-integrin controls the activation of Rac and RhoA in different cell lines (A2780, MDAMB-231 and HT1080 cells) (Jacquemet et al., 2013). The recycling of $\beta 1$-integrin is known to be regulated by Arf6 and Rab11 (Eva et al., 2010, 2012; Powelka et al., 2004) and Rab11 was also implied in the targeted delivery of Src tyrosine kinases to FAs (Bach et al., 2014) where Src contributes to the phosphorylation of FAK (Canel et al., 2013). In addition, $\beta 1$-integrin recruitment can lead to an activation of Rac1 in HeLa cells (O'Toole et al., 2011). Since reggies interact with Rab11a and Src (Liu et al., 2005; Solis et al., 2012; Stuermer et al., 2001, 2004) it is possible that reggies at vesicles and at the plasma membrane coordinate the interactions, underlying FA formation and turnover. Or FAK activation is caused by defective integrin recycling in consequence of loss of reggie- 1 or both.

\section{Conserved role of reggie in targeted delivery of cargo?}

Downregulation of reggie-1 leads to a considerable reduction of reggie-2 (Solis et al., 2007), and vice versa (Saslowsky et al., 2010) so that the present effects on integrin trafficking result from downregulation of reggie- 1 and the concurrent reduction of reggie-2. It is unclear why there are two reggies at cargo vesicles, but their emergence is an evolutionarily early event (Hinderhofer et al., 2009). Reggie- 1 and reggie-2 homologs exist in Drosophila (Rivera-Milla et al., 2006), where the loss of reggie-1 caused shortening of the wingless and hedgehog gradients (Katanaev et al., 2008) presumably due to defects in morphogen deposition and recycling.

Reggies were also needed for growth cone formation and elongation (Koch et al., 2013; Munderloh et al., 2009) and the targeted delivery of $\mathrm{N}$-cadherin as one of many growth and guidance receptors (Bodrikov et al., 2011) in elongating neurites. The Rab11/ARF-6 dependent recycling of integrins was demonstrated by Eva and colleagues as an essential molecular mechanism for the regeneration of axons in mammals (Eva et al., 2010,2012). This is in line with our present results on the interaction of reggie and Rab11a at trafficking cargo vesicles during cell migration (Stuermer, 2010). This implies an interaction of reggies with the cytoskeleton and motor proteins, as exemplified before (Cornfine et al., 2011; Langhorst et al., 2007) and awaits further research. Reggies also interact with the RhoGTPase TC10 (Bodrikov et al., 2011; Fecchi et al., 2006) and RalA which are involved in the exocyst-dependent membrane-directed cargo transport which is further support of the role of reggies in targeted recycling.

In conclusion, our work shows that the emergence of abnormal FAs in reggie-depleted HeLa (and A431) cells results from the influence of reggies on Rab11a dependent recycling. In addition, reggies traffic together with integrins in vesicles that target FAs. The rescue of the FA phenotype after reggie knockdown with Rab11a wt or a CA mutant and the mimic of the phenotype in control cells with a Rab11a DN mutant can be explained by the earlier finding, showing that reggie-1 can interact with Rab11a. Thus our work uncovered a function of reggie in Rab11-controlled and FA-directed trafficking of $\alpha 5$ and $\beta 1$-integrin. This substantiates our view, suggesting a role of reggie in the targeted delivery of cargo to specific sites of the cell. 


\section{Acknowledgements}

This work was supported by the grant STU 112/32-1 from the DFG to CAOS.

\section{Appendix A. Supplementary data}

Supplementary data associated with this article can be found, in the online version, at http://dx.doi.org/10.1016/j.ejcb.2015.07.003

\section{References}

Ait-Slimane, T. Galmes, R., Trugnan, G., Maurice, M., 2009. Basolateral internalization of GPI-anchored proteins occurs via a clathrin-independent flotillin-dependent pathway in polarized hepatic cells. Mol. Biol. Cell 20, 3792-3800.

Arjonen, A., Alanko, J., Veltel, S., Ivaska, J., 2012. Distinct recycling of active and inactive beta1 integrins. Traffic 13, 610-625.

Assaker, G., Ramel, D., Wculek, S.K., Gonzalez-Gaitan, M., Emery, G., 2010. Spatial restriction of receptor tyrosine kinase activity through a polarized endocytic cycle controls border cell migration. Proc. Natl. Acad. Sci. U.S.A. 107, 22558-22563.

Bach, C.T., Murray, R.Z., Owen, D., Gaus, K., O’Neill, G.M., 2014. Tropomyosin Tm5NM1 spatially restricts Src Kinase activity through perturbation of Rab11 vesicle trafficking. Mol. Cell. Biol. 201434 (24), 4436-4446.

Balasubramanian, N., Scott, D.W., Castle, J.D., Casanova, J.E., Schwartz, M.A., 2007 Arf6 and microtubules in adhesion-dependent trafficking of lipid rafts. Nat. Cell Biol. 9, 1381-1391.

Bodrikov, V., Solis, G.P., Stuermer, C.A., 2011. Prion protein promotes growth cone development through reggie/flotillin-dependent $\mathrm{N}$-cadherin trafficking. J. Neurosci. 31, 18013-18025.

Bridgewater, R.E., Norman, J.C., Caswell, P.T., 2012. Integrin trafficking at a glance. J. Cell. Sci. 125, 3695-3701

Canel, M., Serrels, A., Frame, M.C., Brunton, V.G., 2013. E-cadherin-integrin crosstalk in cancer invasion and metastasis. J. Cell Sci. 126, 393-401.

Caswell, P.T., Vadrevu, S., Norman, J.C., 2009. Integrins: masters and slaves of endocytic transport. Nat. Rev. Mol. Cell Biol. 10, 843-853.

Cornfine, S., Himmel, M., Kopp, P., El Azzouzi, K., Wiesner, C., Kruger, M., Rudel, T., Linder, S., 2011. The kinesin KIF9 and reggie/flotillin proteins regulate matrix degradation by macrophage podosomes. Mol. Biol. Cell 22, 202-215.

Emery, G., Ramel, D., 2013. Cell coordination of collective migration by Rab11 and Moesin. Commun. Integr. Biol. 6, e24587.

Eva, R., Crisp, S., Marland, J.R., Norman, J.C., Kanamarlapudi, V., ffrench-Constant, C., Fawcett, J.W., 2012. ARF6 directs axon transport and traffic of integrins and regulates axon growth in adult DRG neurons. J. Neurosci. 32, 10352-10364.

Eva, R., Dassie, E., Caswell, P.T., Dick, G., ffrench-Constant, C., Norman, J.C., Fawcett, J.W., 2010. Rab11 and its effector Rab coupling protein contribute to the trafficking of beta 1 integrins during axon growth in adult dorsal root ganglion neurons and PC12 cells. J. Neurosci. 30, 11654-11669.

Fecchi, K., Volonte, D., Hezel, M.P., Schmeck, K., Galbiati, F., 2006. Spatial and temporal regulation of GLUT4 translocation by flotillin-1 and caveolin-3 in skeletal muscle cells. FASEB J. 20, 705-707.

Glebov, O.O., Bright, N.A., Nichols, B.J., 2006. Flotillin-1 defines a clathrin-independent endocytic pathway in mammalian cells. Nat. Cell Biol. 8, 46-54.

Grant, B.D., Donaldson, J.G., 2009. Pathways and mechanisms of endocytic recycling. Nat. Rev. Mol. Cell Biol. 10, 597-608.

Guillaume, E., Comunale, F., Do Khoa, N., Planchon, D., Bodin, S., Gauthier-Rouviere C., 2013. Flotillin microdomains stabilize cadherins at cell-cell junctions. J. Cell Sci. 126, 5293-5304

Hinderhofer, M., Walker, C.A., Friemel, A., Stuermer, C.A., Moller, H.M., Reuter, A 2009. Evolution of prokaryotic SPFH proteins. BMC Evol. Biol. 9, 10.

Ivanov, A.I., Naydenov, N.G., 2013. Dynamics and regulation of epithelial adherens junctions: recent discoveries and controversies. Int. Rev. Cell Mol. Biol. 303, 27-99.

Jacquemet, G., Green, D.M., Bridgewater, R.E., von Kriegsheim, A., Humphries, M.J., Norman, J.C., Caswell, P.T., 2013. RCP-driven alpha5beta1 recycling suppresses Rac and promotes RhoA activity via the RacGAP1-IQGAP1 complex. J. Cell Biol. 202, 917-935.

Jing, J., Tarbutton, E., Wilson, G., Prekeris, R., 2009. Rab11-FIP3 is a Rab11-binding protein that regulates breast cancer cell motility by modulating the actin cytoskeleton. Eur. J. Cell Biol. 88, 325-341.

Jovic, M., Naslavsky, N., Rapaport, D., Horowitz, M., Caplan, S., 2007. EHD1 regulates beta1 integrin endosomal transport: effects on focal adhesions, cell spreading and migration. J. Cell Sci. 120, 802-814

Katanaev, V.L., Solis, G.P., Hausmann, G., Buestorf, S., Katanayeva, N., Schrock, Y., Stuermer, C.A., Basler, K., 2008. Reggie-1/flotillin-2 promotes secretion of the long-range signalling forms of Wingless and Hedgehog in Drosophila. EMBO J. 27, 509-521.

Kimura, A., Baumann, C.A., Chiang, S.H., Saltiel, A.R., 2001. The sorbin homology domain: a motif for the targeting of proteins to lipid rafts. Proc. Natl. Acad. Sci. U.S.A. 98, 9098-9103.
Kioka, N., Ueda, K., Amachi, T., 2002. Vinexin, CAP/ponsin, ArgBP2: a novel adaptor protein family regulating cytoskeletal organization and signal transduction. Cell Struct. Funct. 27, 1-7.

Koch, J.C., Solis, G.P., Bodrikov, V., Michel, U., Haralampieva, D., Shypitsyna, A., Tonges, L., Bahr, M., Lingor, P., Stuermer, C.A., 2013. Upregulation of reggie-1/flotillin-2 promotes axon regeneration in the rat optic nerve in vivo and neurite growth in vitro. Neurobiol. Dis. 51, 168-176.

Koivusalo, M., Welch, C., Hayashi, H., Scott, C.C., Kim, M., Alexander, T., Touret, N., Hahn, K.M., Grinstein, S., 2010. Amiloride inhibits macropinocytosis by lowering submembranous $\mathrm{pH}$ and preventing Rac1 and Cdc42 signaling. J. Cell Biol. 188, 547-563.

Kuo, J.C., Han, X., Hsiao, C.T., Yates 3rd, J.R., Waterman, C.M., 2011. Analysis of the myosin-II-responsive focal adhesion proteome reveals a role for beta-Pix in negative regulation of focal adhesion maturation. Nat. Cell Biol. 13, 383-393.

Kurrle, N., Vollner, F., Eming, R., Hertl, M., Banning, A., Tikkanen, R., 2013. Flotillins directly interact with gamma-catenin and regulate epithelial cell-cell adhesion. PLoS ONE 8, e84393.

Langhorst, M.F., Jaeger, F.A., Mueller, S., Sven Hartmann, L., Luxenhofer, G., Stuermer, C.A., 2008a. Reggies/flotillins regulate cytoskeletal remodeling during neuronal differentiation via CAP/ponsin and Rho GTPases. Eur. J. Cell Biol. 87, 921-931.

Langhorst, M.F., Reuter, A., Jaeger, F.A., Wippich, F.M., Luxenhofer, G., Plattner, H., Stuermer, C.A., 2008b. Trafficking of the microdomain scaffolding protein reggie-1/flotillin-2. Eur. J. Cell Biol. 87, 211-226.

Langhorst, M.F., Solis, G.P., Hannbeck, S., Plattner, H., Stuermer, C.A., 2007. Linking membrane microdomains to the cytoskeleton: regulation of the lateral mobility of reggie-1/flotillin-2 by interaction with actin. FEBS Lett. 581, 4697-4703.

Liu, J., Deyoung, S.M., Zhang, M., Dold, L.H., Saltiel, A.R., 2005. The stomatin/prohibitin/flotillin/HflK/C domain of flotillin-1 contains distinct sequences that direct plasma membrane localization and protein interactions in 3T3-L1 adipocytes. J. Biol. Chem. 280, 16125-16134.

Margadant, C., Monsuur, H.N., Norman, J.C., Sonnenberg, A., 2011. Mechanisms of integrin activation and trafficking. Curr. Opin. Cell Biol. 23, 607-614.

Munderloh, C., Solis, G.P., Bodrikov, V., Jaeger, F.A., Wiechers, M., Malaga-Trillo, E., Stuermer, C.A., 2009. Reggies/flotillins regulate retinal axon regeneration in the zebrafish optic nerve and differentiation of hippocampal and N2a neurons. J. Neurosci. 29, 6607-6615.

Neumann-Giesen, C., Fernow, I., Amaddii, M., Tikkanen, R., 2007. Role of EGF-induced tyrosine phosphorylation of reggie-1/flotillin-2 in cell spreading and signaling to the actin cytoskeleton. J. Cell Sci. 120, 395-406.

Nobes, C.D., Hall, A., 1999. Rho GTPases control polarity, protrusion, and adhesion during cell movement. J. Cell Biol. 144, 1235-1244.

O’Toole, T.E., Bialkowska, K., Li, X.H., Fox, J.E.B., 2011. Tiam1 is recruited to beta 1-integrin complexes by 14-3-3 zeta where it mediates integrin-induced rac1 activation and motility. J. Cell Physiol. 226, 2965-2978.

Palamidessi, A., Frittoli, E., Garre, M., Faretta, M., Mione, M., Testa, I., Diaspro, A., Lanzetti, L., Scita, G., Di Fiore, P.P., 2008. Endocytic trafficking of Rac is required for the spatial restriction of signaling in cell migration. Cell 134, 135-147.

Payne, C.K., Jones, S.A., Chen, C., Zhuang, X., 2007. Internalization and trafficking of cell surface proteoglycans and proteoglycan-binding ligands. Traffic 8 , 389-401.

Powelka, A.M., Sun, J., Li, J., Gao, M., Shaw, L.M., Sonnenberg, A., Hsu, V.W., 2004. Stimulation-dependent recycling of integrin beta1 regulated by ARF6 and Rab11. Traffic 5, 20-36.

Ramel, D., Wang, X., Laflamme, C., Montell, D.J., Emery, G., 2013. Rab11 regulates cell-cell communication during collective cell movements. Nat. Cell Biol. 15, 317-324.

Rivera-Milla, E., Stuermer, C.A., Malaga-Trillo, E., 2006. Ancient origin of reggie (flotillin), reggie-like, and other lipid-raft proteins: convergent evolution of the SPFH domain. Cell Mol. Life Sci. 63, 343-357.

Saslowsky, D.E., Cho, J.A., Chinnapen, H., Massol, R.H., Chinnapen, D.J., Wagner, J.S., De Luca, H.E., Kam, W., Paw, B.H., Lencer, W.I., 2010. Intoxication of zebrafish and mammalian cells by cholera toxin depends on the flotillin/reggie proteins but not Derlin-1 or -2. J. Clin. Invest. 120, 4399-4409.

Schmidt, M.H., Dikic, I., 2005. The Cbl interactome and its functions. Nat. Rev. Mol. Cell Biol. 6, 907-918.

Schrock, Y., Solis, G.P., Stuermer, C.A., 2009. Regulation of focal adhesion formation and filopodia extension by the cellular prion protein (PrPC). FEBS Lett. 583 389-393.

Sharma, M., Giridharan, S.S., Rahajeng, J., Naslavsky, N., Caplan, S., 2009. MICAL-L1 links EHD1 to tubular recycling endosomes and regulates receptor recycling. Mol. Biol. Cell 20, 5181-5194.

Solis, G.P., Hoegg, M., Munderloh, C., Schrock, Y., Malaga-Trillo, E., Rivera-Milla, E., Stuermer, C.A., 2007. Reggie/flotillin proteins are organized into stable tetramers in membrane microdomains. Biochem. J. 403, 313-322.

Solis, G.P., Hulsbusch, N., Radon, Y., Katanaev, V.L., Plattner, H., Stuermer, C.A., 2013. Reggies/flotillins interact with Rab11a and SNX4 at the tubulo-vesicular recycling compartment and function in transferrin receptor and E-cadherin trafficking. Mol. Biol. Cell. 24 (17), 2689-2702.

Solis, G.P., Schrock, Y., Huelsbusch, N., Wiechers, M., Plattner, H., Stuermer, C.A., 2012. Reggies/flotillins regulate E-cadherin-mediated cell contact formation by affecting EGFR trafficking. Mol. Biol. Cell 23, 1812-1825.

Steffen, A., Ladwein, M., Dimchev, G.A., Hein, A., Schwenkmezger, L., Arens, S., Ladwein, K.I., Margit Holleboom, J., Schur, F., Victor Small, J., Schwarz, J., Gerhard, R., Faix, J., Stradal, T.E., Brakebusch, C., Rottner, K., 2013. Rac function 
is crucial for cell migration but is not required for spreading and focal adhesion formation. J. Cell Sci. 126, 4572-4588.

Stuermer, C.A., 2010. The reggie/flotillin connection to growth. Trends Cell Biol. 20, 6-13.

Stuermer, C.A., Lang, D.M., Kirsch, F., Wiechers, M., Deininger, S.O., Plattner, H., 2001. Glycosylphosphatidyl inositol-anchored proteins and fyn kinase assemble in noncaveolar plasma membrane microdomains defined by reggie-1 and -2. Mol. Biol. Cell 12, 3031-3045.
Stuermer, C.A., Langhorst, M.F., Wiechers, M.F., Legler, D.F., Von Hanwehr, S.H., Guse, A.H., Plattner, H., 2004. PrPc capping in T cells promotes its association with the lipid raft proteins reggie-1 and reggie-2 and leads to signal transduction. FASEB J. 18, 1731-1733.

van Weering, J.R., Verkade, P., Cullen, P.J., 2012. SNX-BAR-mediated endosome tubulation is co-ordinated with endosome maturation. Traffic 13 94-107. 